\title{
9-Fluorenylmethyl (Fm) Disulfides: Biomimetic Precursors for Persulfides
}

Chung-Min Park, ${ }^{\dagger}$ Brett A. Johnson, ${ }^{\dagger}$ Jicheng Duan, ${ }^{\dagger}$ Jeong-Jin Park,${ }^{\S}$ Jacob J. Day, ${ }^{\dagger}$ David Gang, ${ }^{\S}$ Wei-Jun Qian, ${ }^{\star}$ and Ming Xian*, ${ }^{\dagger}$

†Department of Chemistry, Washington State University, Pullman, WA 99164, United States

Biological Sciences Division, Pacific Northwest National Laboratory, Richland, Washington 99352, United States

${ }^{\S}$ Tissue Imaging and Proteomics Laboratory, Washington State University, Pullman, WA 99164, United States

Instrumentation: ${ }^{1} \mathrm{H}$ NMR spectra and ${ }^{13} \mathrm{C}$ NMR were recorded at $300 \mathrm{MHz}$ (Varian, VX 300) and are reported in parts per million ( $\mathrm{ppm})$ on the $\delta$ scale relative to residual $\mathrm{CDCl}_{3}(\delta 7.25)$, DMSO-d6 $(\delta 2.50)$, $\mathrm{CHCl}_{3}(\delta$ 77.0), and DMSO $(\delta$ 39.5) respectively. NMR experiments were performed at room temperature. All reported melting points for solid materials were measured by Fisher-Johns melting point apparatus and not corrected. Mass spectra were recorded using a matrix-assisted laser desorption ionization (MALDI, Bruker Solarix 9.4T), matrix-assisted laser desorption ionization-time of flight (Maldi-Tof/Tof, Bruker UltrafleXtreme), and an electrospray ionization (ESI, Orbitrap Fusion Nano LCMS/MS). Mass data were reported in units of $\mathrm{m} / \mathrm{z}$ for $[\mathrm{M}+\mathrm{H}]^{+}$or $[\mathrm{M}+\mathrm{Na}]^{+}$. Infrared spectra were recorded on a Thermo Scientific Nicolet iS10 (Thin film) and reported in units of $\mathrm{cm}^{-1}$.

Solvents and Reagents: Reagents and solvents employed were of the highest grade available. Reagent grade solvents were used for either chromatography or extraction without further purification before use. Tetrahydrofuran (THF) and dichloromethane (DCM) were directly used from a solvent purifier (Pure Solv, Innovative Technology, inc.). N,N'-Dicyclohexyldicarbodiimide (DCC) and all protected and unprotected natural amino acids were purchased from Advanced ChemTech and used as received. 9Fluorenemethanol (FmOH), S-methyl methanethiosulfonate (MMTS), Iodoacetamide (IAM), 4,4'dithiodipyridine (PySSPy), and 6,6'-dithiodinicotinic acid (PySSPy-A) were purchased from TIC. 1,8Diazabicyclo[5.4.0]undec-7-ene (DBU) and triethylamine (TEA) were purchased from Aldrich and TEA was freshly distilled before use.

Chromatography: The progress of the reactions was monitored by analytical thin layer chromatography (VWR, TLC $60 \mathrm{~F}_{254}$ plates). Plates were visualized first with UV $(254 \mathrm{~nm})$ and then illuminated by CAM stain (2.5 g of ammonium molybdate tetrahydrate and $1 \mathrm{~g}$ of cerium ammonium sulfate in a solution of $10 \%$ sulfuric acid in water) or ninhydrin solution ( $0.3 \%$ ninhydrin in a solution of $3 \%$ acetic acid in 
ethanol). Flash column chromatography was performed using silica gel (230-400 mesh). The solvent compositions for all separations are on a volume/volume (v/v) basis.

\section{Synthesis of FmSSPy and FmSSPy-A}
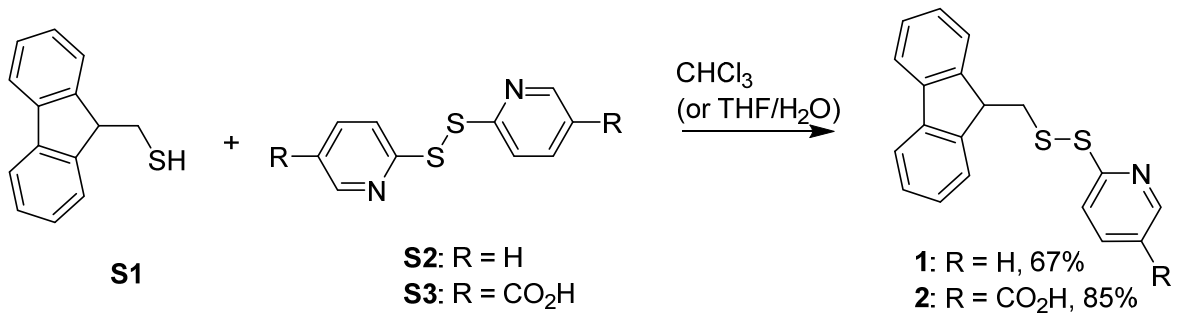

2-(((9H-Fluoren-9-yl)methyl)disulfanyl)pyridine (FmSSPy, 1): To a stirred solution of FmSH (202.6 $\mathrm{mg}, 0.954 \mathrm{mmol})$ in $\mathrm{CHCl}_{3}(5 \mathrm{~mL})$ was added PySSPy $(252.3 \mathrm{mg}, 1.145 \mathrm{mmol})$ followed by TEA $(0.26$ $\mathrm{mL}, 1.90 \mathrm{mmol}$ ) at room temperature. The reaction mixture was stirred overnight. Solvents were removed and the remained residue was extracted with EtOAc. The organic layers were washed with water and brine. Flash column chromatography using 1:5 EtOAc/Hex gave a yellow oil as the product (207 $\mathrm{mg})$ in $67 \%$ yield. ${ }^{1} \mathrm{H}$ NMR $\left(300 \mathrm{MHz}, \mathrm{CDCl}_{3}\right) \delta 8.47(\mathrm{~m}, 1 \mathrm{H}), 7.79-7.09(\mathrm{~m}, 11 \mathrm{H}), 4.32(\mathrm{t}, J=6.2 \mathrm{~Hz}, 1 \mathrm{H})$, $3.52(\mathrm{~m}, 2 \mathrm{H}) ;{ }^{13} \mathrm{C}$ NMR $\left(75 \mathrm{MHz}, \mathrm{CDCl}_{3}\right) \delta 160.17,149.93,145.65,141.27,137.30,127.95,127.34$, $125.15,120.91,120.23,119.93,46.56,44.01$; IR (thin film) 3045.4, 2912.3, 1714.6, 1608.1, 1570.1, 1554.9, 1444.6, 1410.4, 1117.6, 756.4, $737.4 \mathrm{~cm}^{-1}$; HRMS (Maldi) m/z calcd for $\mathrm{C}_{19} \mathrm{H}_{16} \mathrm{NS}_{2}[\mathrm{M}+\mathrm{H}]^{+}$ 322.0724 , found 322.0728 .

6-(((9H-Fluoren-9-yl)methyl)disulfanyl)nicotinic acid (FmSSPy-A, 2): To a stirred solution of FmSH (60.0 mg, $0.283 \mathrm{mmol}$ ) in $18 \mathrm{~mL}$ of 1:1 THF/buffer (pH 8.5) was added 6,6'-dithiodinicotinic acid (136 $\mathrm{mg}, 0.424 \mathrm{mmol}$ ) at room temperature. The reaction mixture was stirred overnight. Organic solvent was removed and the $\mathrm{pH}$ of the remained solution was adjusted to 5 with $1 \mathrm{~N} \mathrm{HCl}$. The mixture was then extracted with EtOAc. The organic layers were washed with water and brine. A flash column chromatography using $10 \% \mathrm{MeOH}$ in DCM gave a yellow solid as the product $(88 \mathrm{mg}$ ) in $85 \%$ yield. mp 190-191 ${ }^{\circ} \mathrm{C} ;{ }^{1} \mathrm{H}$ NMR (300 MHz, DMSO-d $)_{6} \delta 11.7$ (br-s, 1H), 8.84 (s, 1H), $8.17-8.04$ (m, 1H), 7.88 (d, $J=7.4 \mathrm{~Hz}, 2 \mathrm{H}), 7.71(\mathrm{~d}, J=7.3 \mathrm{~Hz}, 2 \mathrm{H}), 7.51(\mathrm{~d}, J=8.5 \mathrm{~Hz}, 1 \mathrm{H}), 7.36(\mathrm{dt}, J=23.5,7.3 \mathrm{~Hz}, 4 \mathrm{H}), 4.36(\mathrm{t}$,

$J=4.5 \mathrm{~Hz}, 1 \mathrm{H}), 3.70(\mathrm{~d}, J=5.2 \mathrm{~Hz}, 2 \mathrm{H}) ;{ }^{13} \mathrm{C} \mathrm{NMR}(75 \mathrm{MHz}) \delta 166.71,165.43,150.54,144.83,141.21$, $138.49,127.83,127.13,124.71,120.00,119.02,46.44,43.88$; IR (thin film) 3064.4, 2910.7, 1707.0, 1585.3, 1551.1, 1444.6, 1364.8, 1292.5, 1273.5, 1254.5, 1144..2, 1129.0, 1091.0, 1022.6, 847.6, 817.2, 767.8, $737.0 \mathrm{~cm}^{-1}$; HRMS (Maldi) $\mathrm{m} / \mathrm{z}$ calcd for $\mathrm{C}_{20} \mathrm{H}_{16} \mathrm{NO}_{2} \mathrm{~S}_{2}[\mathrm{M}+\mathrm{H}]^{+} 366.0622$, found 366.0623 .

\section{Experimental Procedures and Characterization of Compounds 4a-4d:}




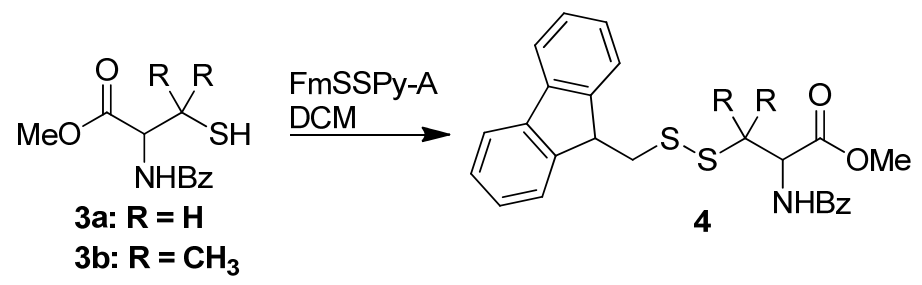

General procedure: To a solution of thiol in DCM or DMSO $(c=0.07 \sim 0.10 \mathrm{M})$ was added 1.1 equiv of FmSSPy-A at room temperature. The color of the reaction immediately became yellow and the reaction was completed in $30 \mathrm{~min}$ at room temperature. The mixture was diluted with DCM and washed with water and brine. A flash column chromatography using a mixture of EtOAc and hexanes on silica gel gave the corresponding products.

Bz-Cys[SFm]-OMe (4a): This compound was obtained as a white solid (155 mg) in 95\% yield. mp 114$116{ }^{\circ} \mathrm{C} ;{ }^{1} \mathrm{H}$ NMR $\left(300 \mathrm{MHz}, \mathrm{CDCl}_{3}\right) \delta 7.84-7.70(\mathrm{~m}, 4 \mathrm{H}), 7.63(\mathrm{~d}, J=7.4 \mathrm{~Hz}, 2 \mathrm{H}), 7.56-7.24(\mathrm{~m}, 7 \mathrm{H})$, $7.05(\mathrm{~d}, J=7.5 \mathrm{~Hz}, 1 \mathrm{H}), 5.06(\mathrm{dt}, J=7.4,5.0 \mathrm{~Hz}, 1 \mathrm{H}), 4.26(\mathrm{t}, J=6.1 \mathrm{~Hz}, 1 \mathrm{H}), 3.71(\mathrm{~s}, 3 \mathrm{H}), 3.41-3.26$ $(\mathrm{m}, 2 \mathrm{H}), 3.21(\mathrm{dd}, J=14.3,4.6 \mathrm{~Hz}, 1 \mathrm{H}), 3.07(\mathrm{dd}, J=14.3,5.4 \mathrm{~Hz}, 1 \mathrm{H}) ;{ }^{13} \mathrm{C} \mathrm{NMR}\left(75 \mathrm{MHz}, \mathrm{CDCl}_{3}\right) \delta$ 207.65, 205.14, 191.32, 171.15, 169.97, 167.20, 145.58, 145.56, 141.35, 133.77, 132.15, 128.89, 127.94, 127.43, 127.36, 127.34, 125.11, 125.08, 120.26, 52.99, 52.72, 46.52, 44.22, 40.65; IR (thin film) 3310.1, 2925.3, 2909.0, 2855.8, 1748.5, 1638.1, 1523.7, 1446.1, 1209.1, 1160.0, 743.2, 726.9, 707.7, .687.9 cm HRMS (Maldi) $\mathrm{m} / \mathrm{z}$ calcd for $\mathrm{C}_{25} \mathrm{H}_{24} \mathrm{NO}_{3} \mathrm{~S}_{2}[\mathrm{M}+\mathrm{H}]^{+} 450.1198$, found 450.1207 .

Bz-D,L-penicillamine[SFm]-OMe (4b): This compound was obtained as a sticky solid (880 mg) in 92\% yield. ${ }^{1} \mathrm{H}$ NMR (300 MHz, $\left.\mathrm{CDCl}_{3}\right) \delta 7.87-7.78(\mathrm{~m}, 2 \mathrm{H}), 7.78-7.71(\mathrm{~m}, 2 \mathrm{H}), 7.69-7.60(\mathrm{~m}, 2 \mathrm{H}), 7.58$ - $7.24(\mathrm{~m}, 7 \mathrm{H}), 6.97(\mathrm{~d}, J=8.6 \mathrm{~Hz}, 1 \mathrm{H}), 4.94(\mathrm{~d}, J=8.7 \mathrm{~Hz}, 1 \mathrm{H}), 4.25$ (t, $J=6.5 \mathrm{~Hz}, 1 \mathrm{H}), 3.75(\mathrm{~s}, 3 \mathrm{H})$, $3.30(\mathrm{ddd}, J=6.7,3.4,0.9 \mathrm{~Hz}, 2 \mathrm{H}), 1.57(\mathrm{~s}, 3 \mathrm{H}), 1.49(\mathrm{~s}, 3 \mathrm{H}) ;{ }^{13} \mathrm{C} \mathrm{NMR}\left(75 \mathrm{MHz}, \mathrm{CDCl}_{3}\right) \delta 170.71$, 167.24, 164.95, 145.61, 145.57, 141.20, 133.90, 132.20, 128.94, 127.92, 127.89, 127.38, 127.34, 127.29, $125.12,125.08,120.20,59.84,53.02,52.66,46.75,45.41,26.82,25.39$; IR (thin film) 3323.1, 2954.2, 2919.9, 1733.6, 1649.9, 1513.1, 1482.6, 1448.4, 1345.8, 1208.9, 741.2, 707.0, 691.7 cm $\mathrm{cm}^{-1}$ HRMS (Maldi) $\mathrm{m} / \mathrm{z}$ calcd for $\mathrm{C}_{27} \mathrm{H}_{28} \mathrm{NO}_{3} \mathrm{~S}_{2}[\mathrm{M}+\mathrm{H}]^{+}$478.1511, found 478.1516 .

Ac-Cys[SFm]-Gly-Phe-OMe (4c): This compound was obtained as a sticky solid (147 mg) in 95\% yield. ${ }^{1} \mathrm{H}$ NMR $\left(300 \mathrm{MHz}, \mathrm{CDCl}_{3}+\mathrm{DMSO}_{-}\right) \delta 7.73(\mathrm{t}, J=5.7 \mathrm{~Hz}, 1 \mathrm{H}), 7.59-7.41(\mathrm{~m}, 4 \mathrm{H}), 7.34(\mathrm{~d}, J=7.5$ $\mathrm{Hz}, 1 \mathrm{H}), 7.24-6.87(\mathrm{~m}, 10 \mathrm{H}), 4.53(\mathrm{dd}, J=7.5,5.7 \mathrm{~Hz}, 1 \mathrm{H}), 4.43(\mathrm{dd}, J=8.1,5.4 \mathrm{~Hz}, 1 \mathrm{H}), 4.08(\mathrm{t}, J=$ $6.4 \mathrm{~Hz}, 1 \mathrm{H}), 3.79$ (d, $J=16.9 \mathrm{~Hz}, 1 \mathrm{H}), 3.54(\mathrm{~d}, J=16.9 \mathrm{~Hz}, 1 \mathrm{H}), 3.45$ (s, 3H), $3.14-3.04$ (m, 2H), 2.97 $2.69(\mathrm{~m}, 4 \mathrm{H}), 1.78(\mathrm{~s}, 3 \mathrm{H}) ;{ }^{13} \mathrm{C}$ NMR $\left(75 \mathrm{MHz}, \mathrm{CDCl}_{3}+\mathrm{DMSO}-d_{6}\right) \quad \delta 171.92,170.75,170.50,168.80$, $145.59,141.02,136.50,129.30,128.53$, 127.71, 127.18, 126.95, 125.08, 119.99, 53.66, 53.57, 52.99, 
52.23, 46.24, 43.45, 42.84, 37.70, 23.04; IR (thin film) 3326.8, 3292.6, 3030.2, 2973.2, 2950.4, 1729.8, 1646.1, 1634.7, 1528.3, 1444.6, 1364.8, 1227.9, 1053.0, 1026.4, 999.7, 821.0, 771.6, 741.0, $699.4 \mathrm{~cm}^{-1}$; HRMS (Maldi) $\mathrm{m} / \mathrm{z}$ calcd for $\mathrm{C}_{31} \mathrm{H}_{34} \mathrm{~N}_{3} \mathrm{O}_{5} \mathrm{~S}_{2}[\mathrm{M}+\mathrm{H}]^{+}$592.1940, found 592.1953 .

Ac-Cys[SFm]-Pro-Phe-OMe (4d): This compound was obtained as a white solid (113 mg) in 95\% yield. mp 73-75 ${ }^{\circ} \mathrm{C} ;{ }^{1} \mathrm{H}$ NMR $\left(300 \mathrm{MHz}, \mathrm{CDCl}_{3}\right) 8.44(\mathrm{~d}, J=4.8 \mathrm{~Hz}, 1 \mathrm{H}), 7.76-7.50(\mathrm{~m}, 4 \mathrm{H}), 7.40-6.95(\mathrm{~m}$, 9H), 6.29 (d, J=7.3 Hz, 1H), $4.88-4.65(\mathrm{~m}, 2 \mathrm{H}), 4.44-4.28(\mathrm{~m}, 1 \mathrm{H}), 4.20$ (t, $J=6.1 \mathrm{~Hz}, 1 \mathrm{H}), 3.64$ (s, $3 \mathrm{H}), 3.61-3.50(\mathrm{~m}, 1 \mathrm{H}), 3.28(\mathrm{~m}, 3 \mathrm{H}), 3.12(\mathrm{dd}, J=13.9,5.4 \mathrm{~Hz}, 1 \mathrm{H}), 3.01-2.79(\mathrm{~m}, 2 \mathrm{H}), 2.69(\mathrm{dd}, J=$ 13.9, $6.4 \mathrm{~Hz}, 1 \mathrm{H}), 2.01(\mathrm{~m}, 1 \mathrm{H}), 1.90(\mathrm{~s}, 3 \mathrm{H}), 1.72(\mathrm{~m}, 2 \mathrm{H}), 1.56(\mathrm{~m}, 1 \mathrm{H}) ;{ }^{13} \mathrm{C} \mathrm{NMR}\left(75 \mathrm{MHz}, \mathrm{CDCl}_{3}\right) \delta$ 172.23 , 170.73, 170.70, 169.96, 149.80, 145.54, 145.51, 141.32, 141.30, 137.65, 136.72, 129.51, 128.60, 127.96, 127.39, 127.36, 127.12, 125.10, 121.35, 120.20, 119.86, 60.70, 53.43, 52.55, 51.04, 47.45, 46.54, 43.73, 39.81, 37.91, 28.57, 24.31, 23.20; IR (thin film) 3315.4, 3285.0, 3049.2, 2946.6, 1741.2, 1634.7, 1543.5, 1444.6, 1414.2, 1281.1, 1208.9, 1117.6, 1026.4, 980.7, 764.0, 741.2, $699.4 \mathrm{~cm}^{-1}$; HRMS (Maldi) $\mathrm{m} / \mathrm{z}$ calcd for $\mathrm{C}_{34} \mathrm{H}_{38} \mathrm{~N}_{3} \mathrm{O}_{5} \mathrm{~S}_{2}[\mathrm{M}+\mathrm{H}]^{+}$632.2253, found 632.2271 .

\section{Generation of Persulfides and Their Trapping with Various Electrophiles:}

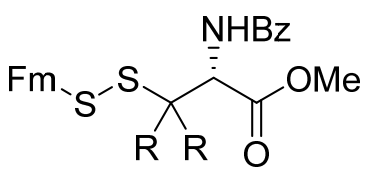

$4 a-4 d$ electrophile THF/DCM/DBU<smiles>[R]SSC([R])([R])[C@H](N)C(=O)OC</smiles>

6a-6k

General procedure: In a round bottom flask, RSSFm and 2 equiv of an electrophile were combined and dissolved in THF or DCM (total concentration $=0.03 \sim 0.05 \mathrm{M}$ ). To the solution was slowly added 2 equiv of DBU in 1-2 $\mathrm{mL}$ of DCM at room temperature. The resulting mixture was stirred for 15 20 min at room temperature. Upon completion of the reaction (monitored by TLC), the solvent was removed under reduced pressure. The residue was dissolved in DCM and washed with $\mathrm{NaHCO}_{3}$, water and brine. The solution was dried over $\mathrm{MgSO}_{4}$ and concentrated under reduce pressure. Purification by flash column chromatography using a mixture of EtOAc and hexanes afforded the corresponding products.

Methyl S-((2-amino-2-oxoethyl)thio)-N-benzoyl-D-cysteinate (6a): This compound was obtained as a solid (39 mg) in 80\% yield. mp 150-151 ${ }^{\circ} \mathrm{C} ;{ }^{1} \mathrm{H}$ NMR (300 MHz, CDCl $3+$ DMSO-d 6 ) ${ }^{1} \mathrm{H} \mathrm{NMR} \mathrm{(300} \mathrm{MHz,}$ Chloroform-d) $\delta 8.22(\mathrm{~d}, J=7.7 \mathrm{~Hz}, 1 \mathrm{H}), 7.58-7.44(\mathrm{~m}, 2 \mathrm{H}), 7.04(\mathrm{~m}, 3 \mathrm{H}), 6.93(\mathrm{~s}, 1 \mathrm{H}), 6.27(\mathrm{~s}, 1 \mathrm{H})$, 4.49 (ddd, $J=9.2,7.7,4.4 \mathrm{~Hz}, 1 \mathrm{H}), 3.33(\mathrm{~s}, 3 \mathrm{H}), 3.09-2.79(\mathrm{~m}, 4 \mathrm{H}) ;{ }^{13} \mathrm{C} \mathrm{NMR}(75 \mathrm{MHz}$, $\left.\mathrm{CDCl}_{3}+\mathrm{DMSO}-d_{6}\right) \delta 171.04,170.89,167.39,133.67,131.57,128.23,127.58,78.14,52.49,52.39,42.41$; IR (thin film) 3353.4, 3296.4, 3193.7, 2987.3, 1726.0, 1661.4, 1627.1, 1532.1, 1334.3, 1239.3, 1159.4, 
1026.4, 840.0, 703.2, 687.0, $672.7 \mathrm{~cm}^{-1}$; HRMS (Maldi) $\mathrm{m} / \mathrm{z}$ calcd for $\mathrm{C}_{13} \mathrm{H}_{17} \mathrm{~N}_{2} \mathrm{O}_{4} \mathrm{~S}_{2}[\mathrm{M}+\mathrm{H}]^{+} 329.0630$, found 329.0631 .

Methyl (S)-3-((2-amino-2-oxoethyl)disulfanyl)-2-benzamido-3-methylbutanoate $\quad(6 \mathbf{b})$ : This compound was obtained as a white solid (41 mg) in 95\% yield. mp 104-105 ${ }^{\circ} \mathrm{C} ;{ }^{1} \mathrm{H}$ NMR (300 MHz, $\left.\mathrm{CDCl}_{3}\right) \delta 7.87-7.73(\mathrm{~m}, 2 \mathrm{H}), 7.57-7.38(\mathrm{~m}, 3 \mathrm{H}), 6.98(\mathrm{~d}, J=9.1 \mathrm{~Hz}, 1 \mathrm{H}), 6.57(\mathrm{~s}, 1 \mathrm{H}), 6.02(\mathrm{~s}, 1 \mathrm{H})$, $4.97(\mathrm{~d}, J=9.2 \mathrm{~Hz}, 1 \mathrm{H}), 3.77$ (s, 3H), $3.61-3.32(\mathrm{~m}, 2 \mathrm{H}), 1.47$ (d, $J=6.8 \mathrm{~Hz}, 6 \mathrm{H}) ;{ }^{13} \mathrm{C} \mathrm{NMR}(75 \mathrm{MHz}$, $\left.\mathrm{CDCl}_{3}\right) \delta 170.93,170.80,167.57,133.71,132.38,128.98,127.44,59.26,53.20,52.79,43.42,26.34$, 24.55; IR (thin film) 3402.8, 3300.2, 3246.9, 3205.1, 2931.3, 1718.4, 1638.5, 1509.3, 1482.6, 1368.6, 1220.3, 1148.3, 1110.0, $691.7 \mathrm{~cm}^{-1}$; HRMS (Maldi) m/z calcd for $\mathrm{C}_{15} \mathrm{H}_{21} \mathrm{~N}_{2} \mathrm{O}_{4} \mathrm{~S}_{2}[\mathrm{M}+\mathrm{H}]^{+} 357.0943$, found 357.0946 .

Methyl N-benzoyl-S-((3-methoxy-3-oxopropyl)thio)-D-cysteinate (6c): This compound was obtained as a sticky oil (56 mg) in 64\% yield. ${ }^{1} \mathrm{H}$ NMR $\left(300 \mathrm{MHz}, \mathrm{CDCl}_{3}\right) \delta 7.91-7.73(\mathrm{~m}, 2 \mathrm{H}), 7.58-7.32(\mathrm{~m}$, $3 \mathrm{H}), 7.10(\mathrm{~d}, J=7.5 \mathrm{~Hz}, 1 \mathrm{H}), 5.01(\mathrm{dt}, J=7.5,5.0 \mathrm{~Hz}, 1 \mathrm{H}), 3.78(\mathrm{~s}, 3 \mathrm{H}), 3.65(\mathrm{~s}, 3 \mathrm{H}), 3.20-3.04(\mathrm{~m}$, $2 \mathrm{H}), 2.83-2.75(\mathrm{~m}, 2 \mathrm{H}), 2.57(\mathrm{td}, J=7.2,0.8 \mathrm{~Hz}, 2 \mathrm{H}) ;{ }^{13} \mathrm{C} \mathrm{NMR}\left(75 \mathrm{MHz}, \mathrm{CDCl}_{3}\right) \delta 172.30,171.47$, $167.27,133.77,132.16,128.84,127.47,127.41,53.04,52.63,52.09,34.67,34.52,27.81$; IR (thin film) 3321.3, 2950.4, 2923.7, 1737.4, 1649.9, 1520.7, 1482.6, 1433.2, 1353.4, 1208.9, 1174.6, 908.6, 729.8, $684.1 \mathrm{~cm}^{-1}$; HRMS (Maldi) $\mathrm{m} / \mathrm{z}$ calcd for $\mathrm{C}_{15} \mathrm{H}_{20} \mathrm{NO}_{5} \mathrm{~S}_{2}[\mathrm{M}+\mathrm{H}]^{+} 358.0783$, found 358.0784.

Methyl $N$-benzoyl-S-(((2,5,6-trimethyl-1,7-dioxo-1H,7H-pyrazolo[1,2-a]pyrazol-3-yl)methyl)thio)D-cysteinate (6d): This compound was obtained as an yellow solid (38 mg) in 74\% yield. mp 175-176 ${ }^{\circ} \mathrm{C} ;{ }^{1} \mathrm{H}$ NMR (300 MHz, $\left.\mathrm{CDCl}_{3}\right) \delta 7.81(\mathrm{~m}, 2 \mathrm{H}), 7.63-7.33(\mathrm{~m}, 3 \mathrm{H}), 7.02(\mathrm{~d}, J=7.4 \mathrm{~Hz}, 1 \mathrm{H}), 5.09$ (q, $=6.1 \mathrm{~Hz}, 1 \mathrm{H}), 3.98-3.82(\mathrm{~m}, 2 \mathrm{H}), 3.79(\mathrm{~s}, 3 \mathrm{H}), 3.25(\mathrm{ddd}, J=55.3,14.1,5.4 \mathrm{~Hz}, 2 \mathrm{H}), 2.33(\mathrm{~s}, 3 \mathrm{H}), 1.90$ $(\mathrm{s}, 3 \mathrm{H}), 1.80(\mathrm{~s}, 3 \mathrm{H}) ;{ }^{13} \mathrm{C}$ NMR $\left(75 \mathrm{MHz}, \mathrm{CDCl}_{3}\right) \delta 170.96,167.32,160.88,160.28,146.24,144.77$, $133.51,132.34,128.92,127.40,115.82,113.07,53.31,52.28,40.61,32.22,12.14,7.64,7.09$; IR (thin film) 3307.8, 2954.2, 2916.1, 1729.8, 1653.7, 1524.5, 1402.8, 1418.0, 1292.5, 1227.9, 1170.8, 1144.2, 988.3, 745.0, 718.4, 695.5 $\mathrm{cm}^{-1}$; HRMS (Maldi) $\mathrm{m} / \mathrm{z}$ calcd for $\mathrm{C}_{21} \mathrm{H}_{24} \mathrm{~N}_{3} \mathrm{O}_{5} \mathrm{~S}_{2}[\mathrm{M}+\mathrm{H}]^{+} 462.1157$, found 462.1159 .

Methyl $\mathbf{N}$-benzoyl-S-(methyldisulfanyl)-D-cysteinate (6e): This compound was obtained as a white solid (23 mg) in 53\% yield. mp 64-65 ${ }^{\circ} \mathrm{C}$; ${ }^{1} \mathrm{H}$ NMR (300 MHz, $\left.\mathrm{CDCl}_{3}\right) \delta 7.84(\mathrm{dt}, J=6.9,1.5 \mathrm{~Hz}, 2 \mathrm{H})$, $7.62-7.38(\mathrm{~m}, 3 \mathrm{H}), 7.07$ (d, $J=7.4 \mathrm{~Hz}, 1 \mathrm{H}), 5.16(\mathrm{dt}, J=7.3,4.8 \mathrm{~Hz}, 1 \mathrm{H}), 3.82(\mathrm{~s}, 3 \mathrm{H}), 3.61-3.44$ (m, 2H), $2.54(\mathrm{~s}, 3 \mathrm{H}) ;{ }^{13} \mathrm{C} \mathrm{NMR}\left(75 \mathrm{MHz}, \mathrm{CDCl}_{3}\right) \delta 171.03,167.24,133.80,132.20,128.87,127.43,52.32$, 49.12, 40.60, 22.67; IR (thin film) 3353.4, 2946.6, 2916.1, 1741.2, 1638.5, 1513.1, 1486.4, 1429.4, 1296.3, 1258.3, 1231.7, 1208.9, 1163.2, 1007.3, 718.4, 684.1 $\mathrm{cm}^{-1}$; HRMS (Maldi) $\mathrm{m} / \mathrm{z}$ calcd for $\mathrm{C}_{12} \mathrm{H}_{16} \mathrm{NO}_{3} \mathrm{~S}_{3}[\mathrm{M}+\mathrm{H}]^{+}$318.0287, found 318.0293 . 
Methyl-2-benzamido-3-((3-methoxy-3-oxopropyl)disulfanyl)-3-methylbutanoate (6f): This compound was obtained as a sticky oil $(43 \mathrm{mg})$ in $82 \%$ yield. ${ }^{1} \mathrm{H}$ NMR $\left(300 \mathrm{MHz}, \mathrm{CDCl}_{3}\right) \delta 7.90-7.73(\mathrm{~m}, 2 \mathrm{H})$, $7.59-7.37$ (m, 3H), 6.93 (d, J=8.8 Hz, 1H), 4.91 (d, J=8.7 Hz, 1H), 3.77 (s, 3H), 3.67 (s, 3H), $3.05-$ $2.88(\mathrm{~m}, 2 \mathrm{H}), 2.69(\mathrm{t}, J=7.1 \mathrm{~Hz}, 2 \mathrm{H}), 1.52(\mathrm{~s}, 3 \mathrm{H}), 1.46(\mathrm{~s}, 3 \mathrm{H}) ;{ }^{13} \mathrm{C} \mathrm{NMR}\left(75 \mathrm{MHz}, \mathrm{CDCl}_{3}\right) \delta 172.19$, 170.68, 167.23, 133.88, 132.19, 128.91, 127.37, 59.70, 52.89, 52.67, 52.15, 35.03, 34.13, 26.48, 25.21; IR (thin film) 3334.1, 2950.4, 2927.5, 1729.8, 1659.7, 1513.1, 1478.4, 1342.0, 1299.3, 1205.1, 1167.0, 1117.6, 1014.9, 710.8, $691.7 \mathrm{~cm}^{-1}$; HRMS (Maldi) $\mathrm{m} / \mathrm{z}$ calcd for $\mathrm{C}_{17} \mathrm{H}_{24} \mathrm{NO}_{5} \mathrm{~S}_{2}[\mathrm{M}+\mathrm{H}]^{+} 386.1096$, found 386.1099 .

\section{Methyl-2-benzamido-3-methyl-3-(((2,5,6-trimethyl-1,7-dioxo-1H,7H-pyrazolo[1,2-a]pyrazol-3-}

yl)methyl)disulfanyl)butanoate (6g): This compound was obtained as an yellow solid (48 $\mathrm{mg}$ ) in 92\% yield. mp $72-75{ }^{\circ} \mathrm{C} ;{ }^{1} \mathrm{H}$ NMR $\left(300 \mathrm{MHz}, \mathrm{CDCl}_{3}\right) \delta 7.85-7.71(\mathrm{~m}, 2 \mathrm{H}), 7.60-7.40(\mathrm{~m}, 3 \mathrm{H}), 6.82(\mathrm{~d}, J=$ $9.3 \mathrm{~Hz}, 1 \mathrm{H}), 5.01(\mathrm{~d}, J=9.3 \mathrm{~Hz}, 1 \mathrm{H}), 4.04-3.82(\mathrm{~m}, 2 \mathrm{H}), 3.79$ (s, 3H), 2.38 (s, 3H), 1.89 (s, 3H), 1.81 (s, $3 \mathrm{H}), 1.51(\mathrm{~s}, 3 \mathrm{H}), 1.47(\mathrm{~s}, 3 \mathrm{H}) ;{ }^{13} \mathrm{C} \mathrm{NMR}\left(75 \mathrm{MHz}, \mathrm{CDCl}_{3}\right) \delta 170.60,167.33,160.86,160.33,146.11$, $144.64,133.67,132.45,129.02,127.31,115.44,113.14,58.88,53.81,52.87,33.92,26.24,24.59,12.08$, 7.79, 7.11; IR (thin film) 3227.9, 3197.5, 2931.3, 2916.1, 1737.4, 1663.7, 1433.2, 1406.6, 1216.5, 1151.8, 1079.6, 1030.2, 718.4, $695.5 \mathrm{~cm}^{-1}$; HRMS (Maldi) m/z calcd for $\mathrm{C}_{23} \mathrm{H}_{28} \mathrm{~N}_{3} \mathrm{O}_{5} \mathrm{~S}_{2}[\mathrm{M}+\mathrm{H}]^{+} 490.1470$, found 490.1465 .

Methyl 2-benzamido-3-(benzyldisulfanyl)-3-methylbutanoate (6h): This compound was obtained as a sticky solid (39 mg) in 95\% yield. ${ }^{1} \mathrm{H}$ NMR $\left(300 \mathrm{MHz}, \mathrm{CDCl}_{3}\right) \delta 7.85-7.77(\mathrm{~m}, 2 \mathrm{H}), 7.58-7.39$ (m, $3 \mathrm{H}), 7.34-7.21(\mathrm{~m}, 5 \mathrm{H}), 6.98(\mathrm{~d}, J=8.7 \mathrm{~Hz}, 1 \mathrm{H}), 4.93(\mathrm{~d}, J=8.7 \mathrm{~Hz}, 1 \mathrm{H}), 4.06-3.87$ (m, 2H), 3.77 (s, $3 \mathrm{H}), 1.51(\mathrm{~s}, 3 \mathrm{H}), 1.46(\mathrm{~s}, 3 \mathrm{H}) ;{ }^{13} \mathrm{C} \mathrm{NMR}\left(75 \mathrm{MHz}, \mathrm{CDCl}_{3}\right) \delta 170.69,167.23,136.85,133.93,132.18$, $129.53,128.91,128.85,127.88,127.39,59.95,52.92,52.64,45.47,26.71,25.32$; IR (thin film) 3364.8 , 2965.6, 2946.6, 2923.7, 1741.2, 1653.7, 1509.3, 1478.8, 1452.2, 1429.4, 1334.3, 1205.1, 1163.2, 1022.6, 764.0, $695.5 \mathrm{~cm}^{-1}$; HRMS (Maldi) $\mathrm{m} / \mathrm{z}$ calcd for $\mathrm{C}_{20} \mathrm{H}_{24} \mathrm{NO}_{3} \mathrm{~S}_{2}[\mathrm{M}+\mathrm{H}]^{+} 390.1198$, found 390.1201 .

Methyl-2-benzamido-3-methyl-3-(methyltrisulfanyl)butanoate (6i): This compound was obtained as a white solid (39 mg) in 90\% yield. mp 63-64 ${ }^{\circ} \mathrm{C} ;{ }^{1} \mathrm{H} \mathrm{NMR}\left(300 \mathrm{MHz}, \mathrm{CDCl}_{3}\right) \delta 7.97-7.72(\mathrm{~m}, 2 \mathrm{H}), 7.61$ - $7.34(\mathrm{~m}, 3 \mathrm{H}), 6.95(\mathrm{~d}, \mathrm{~J}=8.7 \mathrm{~Hz}, 1 \mathrm{H}), 4.93(\mathrm{~m}, 1 \mathrm{H}), 3.78(\mathrm{~m}, 3 \mathrm{H}), 2.47$ (m, 3H), 1.66 - $1.40(\mathrm{~m}, 6 \mathrm{H})$; ${ }^{13} \mathrm{C}$ NMR $\left(75 \mathrm{MHz}, \mathrm{CDCl}_{3}\right) \delta 170.62,167.36,133.97,132.17,128.91,128.88,127.43,127.37,59.79$, 53.56, 52.70, 26.59, 25.54, 22.82; IR (thin film) 3380.0, 2977.0, 2942.8, 2916.1, 1726.0, 1665.2, 1509.3, 1482.6, 1429.4, 1361.0, 1307.7, 1262.1, 1220.3, 1132.8, 1072.0, 1014.9, 756.4, 703.2, $691.7 \mathrm{~cm}^{-1}$; HRMS (Maldi) $\mathrm{m} / \mathrm{z}$ calcd for $\mathrm{C}_{14} \mathrm{H}_{20} \mathrm{NO}_{3} \mathrm{~S}_{3}[\mathrm{M}+\mathrm{H}]^{+} 346.0600$, found 346.0600 .

Ac-Cys[SCH $\mathbf{C O N H}_{2}$ ]-Gly-Phe-OMe (6j) This compound was obtained as a white solid (22 $\mathrm{mg}$ ) in $69 \%$ yield. mp 135-138 ${ }^{\circ} \mathrm{C} ;{ }^{1} \mathrm{H}$ NMR (300 MHz, CDCl $\left.{ }_{3}+\mathrm{DMSO}-\mathrm{d}_{6}\right) \delta 8.01$ (br-s, $1 \mathrm{H}, \mathrm{N} \underline{\mathrm{H}}$ ), 7.60 (br-s, $1 \mathrm{H}$, 


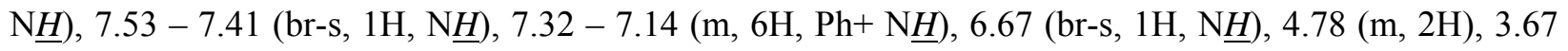
$(\mathrm{s}, 3 \mathrm{H}), 3.56(\mathrm{~m}, 2 \mathrm{H}), 3.49(\mathrm{~s}, 2 \mathrm{H}), 3.24(\mathrm{~m}, 1 \mathrm{H}), 3.11(\mathrm{~m}, 3 \mathrm{H}), 2.03(\mathrm{~s}, 3 \mathrm{H}),{ }^{13} \mathrm{C} \mathrm{NMR}(75 \mathrm{MHz}$, $\left.\mathrm{CDCl}_{3}+\mathrm{DMSO}-d_{6}\right) 171.54,170.60,170.46,170.30,168.67,136.64,128.90,128.09,126.42,53.46,51.71$, 48.16, 42.14, 37.79, 37.04, 28.40, 26.14, 23.46, 22.57; IR (thin film) 3307.8, 3300.2, 3007.4, 2942.8, 1729.8, 1657.5, 1630.9, 1532.1, 1452.2, 1414.2, 1220.3, 1030.2, 737.4, 703.2, $668.9 \mathrm{~cm}^{-1}$; HRMS (Maldi) $\mathrm{m} / \mathrm{z}$ calcd for $\mathrm{C}_{19} \mathrm{H}_{27} \mathrm{~N}_{4} \mathrm{O}_{6} \mathrm{~S}_{2}[\mathrm{M}+\mathrm{H}]^{+}$471.1372, found 471.1378 .

Ac-Cys[SCH $\mathbf{C O N H}_{2}$ ]-Pro-Phe-OMe (6k): This compound was obtained as a white solid (23 mg) in $64 \%$ yield. mp $59{ }^{\circ} \mathrm{C} ;{ }^{1} \mathrm{H}$ NMR $\left(300 \mathrm{MHz}, \mathrm{CDCl}_{3}\right) \delta 7.44(\mathrm{~d}, J=6.5 \mathrm{~Hz}, 1 \mathrm{H}, \mathrm{N} \underline{H}), 7.16(\mathrm{~m}, 6 \mathrm{H}$,

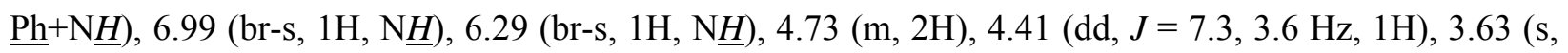
$3 \mathrm{H}), 3.55-3.39$ (m, 4H), $3.19-3.08$ (m, 2H), 3.03 - $2.86(\mathrm{~m}, 2 \mathrm{H}), 2.03$ (m, 1H), 1.93 (s, 3H), 1.79 $1.66(\mathrm{~m}, 3 \mathrm{H}) ;{ }^{13} \mathrm{C}$ NMR $\left(75 \mathrm{MHz}, \mathrm{CDCl}_{3}\right) \delta 172.33,171.57,171.02,170.55,166.57,136.87,129.46$, $128.63,127.12,61.04,55.08,53.57,52.57,49.15,42.97,38.38,29.18,26.96,24.16,23.01$; IR (thin film) 3296.4, 3277.4, 2950.4, 2927.5, 1737.4, 1620.1, 1535.9, 1524.5, 1440.8, 1368.6, 1224.1, 1212.7, 737.4, 691.7, $668.9 \mathrm{~cm}^{-1}$; HRMS (Maldi) $\mathrm{m} / \mathrm{z}$ calcd for $\mathrm{C}_{22} \mathrm{H}_{31} \mathrm{~N}_{4} \mathrm{O}_{6} \mathrm{~S}_{2}[\mathrm{M}+\mathrm{H}]^{+}$511.1685, found 511.1691.

\section{Reaction between $4 b$ and MSBT}

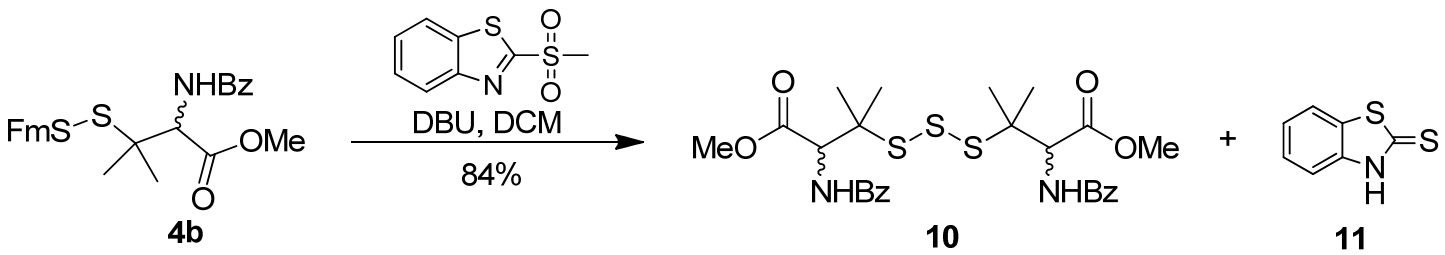

Compound 10: ${ }^{1} \mathrm{H}$ NMR (300 MHz, $\left.\mathrm{CDCl}_{3}\right) \delta 7.92$ - $7.72(\mathrm{~m}, 4 \mathrm{H}), 7.57$ - 7.35 (m, 6H), 6.90 (m, 2H), $4.94(\mathrm{~m}, 2 \mathrm{H}), 3.77$ (s, 3H), 3.76 (s, 3H), 1.50 (m, 12H); IR (thin film) 3364.8, 2973.2, 2950.4, 2923.7, 1745.0, 1653.7, 1505.5, 1482.6, 1429.5, 1338.2, 1205.1, 1117.6, 1014.9, 714.6, $687.9 \mathrm{~cm}^{-1} ;{ }^{13} \mathrm{C}$ NMR $(75$ $\left.\mathrm{MHz}, \mathrm{CDCl}_{3}\right) \delta 170.59,167.33,133.88,132.20,128.88,127.44,59.56,54.24,52.73,26.61,26.51,25.50$, 25.18; MS (ESI) $\mathrm{m} / \mathrm{z}$ calcd for $\mathrm{C}_{26} \mathrm{H}_{32} \mathrm{~N}_{2} \mathrm{NaO}_{6} \mathrm{~S}_{3}[\mathrm{M}+\mathrm{Na}]^{+}$587.1, found 587.2.

Compound 11: ${ }^{1} \mathrm{H}$ NMR (300 MHz, DMSO-d $\left.{ }_{6}+\mathrm{CDCl}_{3}\right) \delta 13.35$ (br-s, $\left.1 \mathrm{H}, \mathrm{N} \underline{\mathrm{H}}\right), 7.41-7.05(\mathrm{~m}, 4 \mathrm{H}) .{ }^{13} \mathrm{C}$ NMR (75 MHz, DMSO) $\delta 190.69,141.71,130.16,127.03,124.32,121.27,112.88$. MS (ESI) m/z calcd for $\mathrm{C}_{7} \mathrm{H}_{5} \mathrm{NNaS}_{2}[\mathrm{M}+\mathrm{Na}]^{+}$190.0, found 190.1.

\section{Crossover experiment between Bz-DL-penicillamine[SFm]-OMe and Ac-DL-penicillamine[SSBt]- $\mathrm{ONH}\left(\mathrm{CH}_{2}\right)_{4}$.}




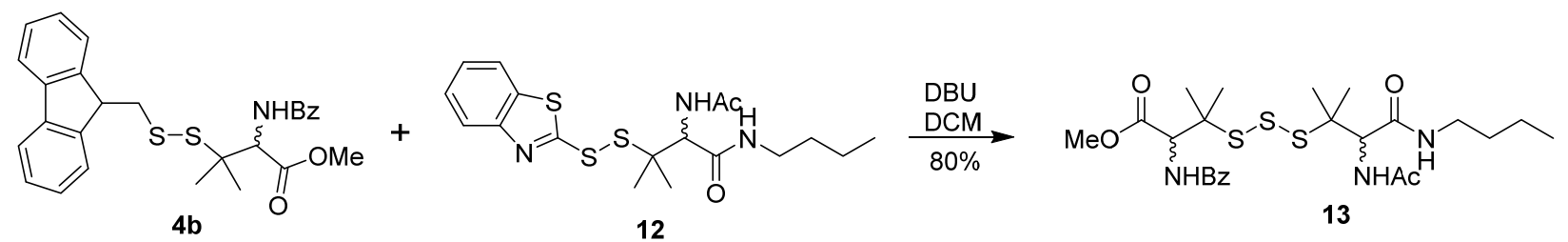

Preparation of compound 12: 2,2'-Dibenzothiazolyl disulfide (2.16 g, $6.50 \mathrm{mmol})$ was dissolved into 250 $\mathrm{mL}$ of $\mathrm{CHCl}_{3}$. To this solution was added a DL-penicillamine derivative $(1.18 \mathrm{~g}, 4.80 \mathrm{mmol})$. The reaction mixture was stirred at room temperature for $48 \mathrm{~h}$. Excess solvent was removed under reduced pressure and then remaining 2,2'-dibenzothiazolyl disulfide was filtered using DCM. The crude product was then purified by flash column chromatography using 3\% MeOH in DCM to give the product 12 (2.54 g) in 95\% yield as white solid. mp 167-168 ${ }^{\circ} \mathrm{C}$; ${ }^{1} \mathrm{H}$ NMR (300 MHz, $\left.\mathrm{CDCl}_{3}\right) \delta 7.95$ (br-s, 1H), 7.72 (ddd, $J=9.4,8.2,1.2 \mathrm{~Hz}, 2 \mathrm{H}), 7.31(\mathrm{~m}, 2 \mathrm{H}), 6.80$ (br-s, 1H), 4.78 (d, $J=9.0 \mathrm{~Hz}, 1 \mathrm{H}), 3.37$ (m, 1H), 3.13 (m, $1 \mathrm{H}), 1.95(\mathrm{~s}, 3 \mathrm{H}), 1.54-1.39(\mathrm{~m}, 5 \mathrm{H}), 1.39-1.23(\mathrm{~m}, 5 \mathrm{H}), 0.83(\mathrm{t}, J=7.3 \mathrm{~Hz}, 3 \mathrm{H}) ;{ }^{13} \mathrm{C} \mathrm{NMR}(75 \mathrm{MHz}$, $\left.\mathrm{CDCl}_{3}\right) \delta 172.21,170.34,168.92,136.08,126.65,125.14,121.82,121.52,58.77,55.41,39.75,31.63$, 25.30, 24.65, 23.59, 20.48, 13.96; IR (thin film, $\mathrm{cm}^{-1}$ ) 3273, 3080, 2951, 2864, 1683, 1634, 1564, 1455 , 1424, 1380, 1363, 1002, 749, 721; MS (ESI) $\mathrm{m} / \mathrm{z}$ calcd for $\mathrm{C}_{18} \mathrm{H}_{25} \mathrm{~N}_{3} \mathrm{NaO}_{2} \mathrm{~S}_{3}[\mathrm{M}+\mathrm{Na}]^{+}$434.0, found 434.1.

Compound 13 (diastereomers): ${ }^{1} \mathrm{H}$ NMR $\left(300 \mathrm{MHz}, \mathrm{CDCl}_{3}\right) \delta 7.76(\mathrm{~m}, 2 \mathrm{H}), 7.41(\mathrm{~m}, 3 \mathrm{H}), 6.89(\mathrm{~m}, 1 \mathrm{H})$, $6.52(\mathrm{dd}, J=24.0,8.6 \mathrm{~Hz}, 2 \mathrm{H}), 4.91(\mathrm{~m}, 1 \mathrm{H}), 4.59$ (d, $J=8.7 \mathrm{~Hz}, 1 \mathrm{H}), 3.72(\mathrm{~s}, 3 \mathrm{H}), 3.32-2.99$ (m, 2H), $1.94(\mathrm{~m}, 3 \mathrm{H}), 1.60-1.16(\mathrm{~m}, 16 \mathrm{H}), 0.83(\mathrm{t}, J=7.1 \mathrm{~Hz}, 3 \mathrm{H}) ;{ }^{13} \mathrm{C}$ NMR $\left(75 \mathrm{MHz}, \mathrm{CDCl}_{3}\right) \delta 170.75$, 170.66, 170.37, 170.30, 168.98, 168.95, 167.37, 167.35, 133.86, 133.82, 132.23, 128.91, 127.51, 127.46, $59.72,59.56,58.91,58.54,54.39,54.29,54.18,54.12,52.78,52.75,39.70,39.66,31.60,26.72,26.62$, 25.62, 25.45, 25.25, 25.18, 24.97, 23.55, 20.36, 13.94; IR (thin film) 3289.0, 2966.2, 2953.9, 2945.7, $1744.4,1642.2$, 1515.6, 1478.8, 1450.2, 1433.8, 1360.3, 1339.8, 1205.0, 1115.1, 710.6, $690.1 \mathrm{~cm}^{-1}$; HRMS (Maldi) $\mathrm{m} / \mathrm{z}$ calcd for $\mathrm{C}_{24} \mathrm{H}_{38} \mathrm{~N}_{3} \mathrm{O}_{5} \mathrm{~S}_{3}[\mathrm{M}+\mathrm{H}]^{+}$544.1968, found 544.1970.

\section{Labeling of all free thiols on reduced BSA}

Freshly prepared $50 \mathrm{mM}$ HEPES buffer ( $\mathrm{pH}$ 7.7) was used. $10 \mathrm{mg}$ of BSA was dissolved in HEPES buffer to obtain a $150 \mu \mathrm{M}$ stock solution. A $200 \mathrm{mM}$ FmSSPy-A solution was prepared in DMF. A 10 $\mathrm{mM}$ DTNB solution was prepared in PBS buffer (pH 8.0). A $100 \mathrm{mM}$ monobromobimane stock solution in DMF was freshly prepared.

\section{Procedure:}

1. Reduction of BSA: To a $700 \mu \mathrm{L}$ of BSA solution $(10 \mathrm{mg} / \mathrm{mL}, 0.150 \mathrm{mM})$ was added $28.0 \mu \mathrm{L}$ of 500 mM DTT at room temperature. The mixture was stirred at $37{ }^{\circ} \mathrm{C}$ for $1 \mathrm{~h}$ in dark. The excess DTT was removed by Zeba desalting column with PBS buffer $(2 \times) .120 \mu \mathrm{L}$ of aliquot was taken and the 
concentration of free thiols was determined by Ellman's reagent (DTNB). Zeba desalting column can efficiently remove unreacted DTT. One time desalting removed $>99.9 \%$ of DTT, while two time desalting can remove DTT completely. The Ellman's assay showed the conversion of BSA disulfide to free thiol is about $52.2 \%$ after DTT reduction (Figure S1).

2. FmSSPy-A treatment: To a $550 \mu \mathrm{L}$ of purified and reduced BSA solution was slowly added $50.0 \mu \mathrm{L}$ of $200 \mathrm{mM}$ FmSSPy-A. The mixture was incubated at $37{ }^{\circ} \mathrm{C}$ for $1 \mathrm{~h}$ in dark. The proteins were purified by Zeba desalting column $(2 \mathrm{~mL}) .120 \mu \mathrm{L}$ of aliquot was taken and the concentration of free thiols on BSA was determined by Ellman's reagent (DTNB). Measurement: $5 \mu \mathrm{L}$ of Ellman's Reagent solution (10 $\mathrm{mM}$ ) and $250 \mathrm{uL}$ of Ellman's reaction buffer were combined in a test tube. To the test tube was added 25 $\mu \mathrm{L}$ of BSA aliquots (treated and untreated separately). The mixture was gently swirled and incubated at room temperature for $15 \mathrm{~min}$. UV intensity of the solution was measured at $410 \mathrm{~nm}$ and recorded (Figure S1).

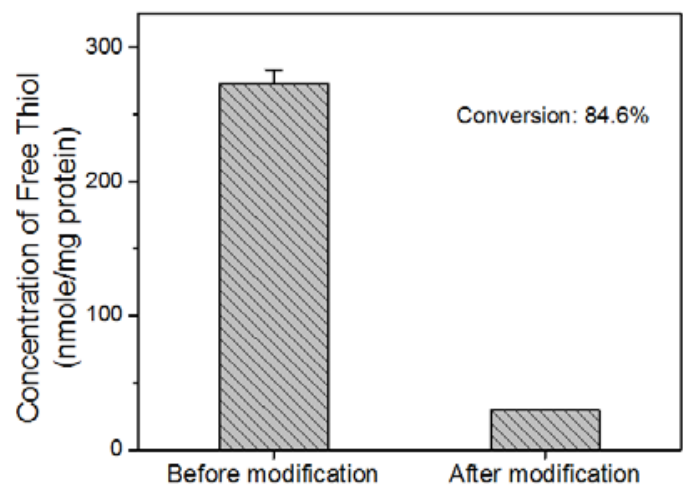

Figure S1. Determination of the concentration of free thiols before/after treatment of FmSSPy-A.

3. Monobromobimane treatment: To $225 \mu \mathrm{L}$ of FmSSPy-A treated-BSA solution was added $25 \mathrm{uL}$ of $100 \mathrm{mM}$ monobromobimane (final conc. $=10 \mathrm{mM}$ ) then the mixture was vortexed for $10 \mathrm{~min}$. To the mixture was added $50 \mathrm{uL}$ of $1 \mathrm{M} \mathrm{DBU}$ in DMF (final conc. $=200 \mathrm{mM}$ ) and stirred for $1 \mathrm{~h}$ at room temperature in dark. The labeled BSA was purified by Zeba column.

Protein digestion: The concentrations of protein samples (DTT-treated BSA, FmSSPy-A-treated BSA, monobromobimane-treated BSA) were measured by BCA. Each protein sample ( $200 \mu \mathrm{L}$ from 1 $\mathrm{mg} / \mathrm{mL}$ of a protein) was digested by $5 \mu \mathrm{g}$ of trypsin for overnight (about $16 \mathrm{~h}$ ) at $37{ }^{\circ} \mathrm{C}$. Without further purification, tryptic peptides were subjected to LC-MS/MS analysis (Figure S2). The peak area of peptide ion in the extracted ion chromatogram was used to calculate the conversion of reaction at different cysteine residues in BSA. The results were summarized in Table S1. 

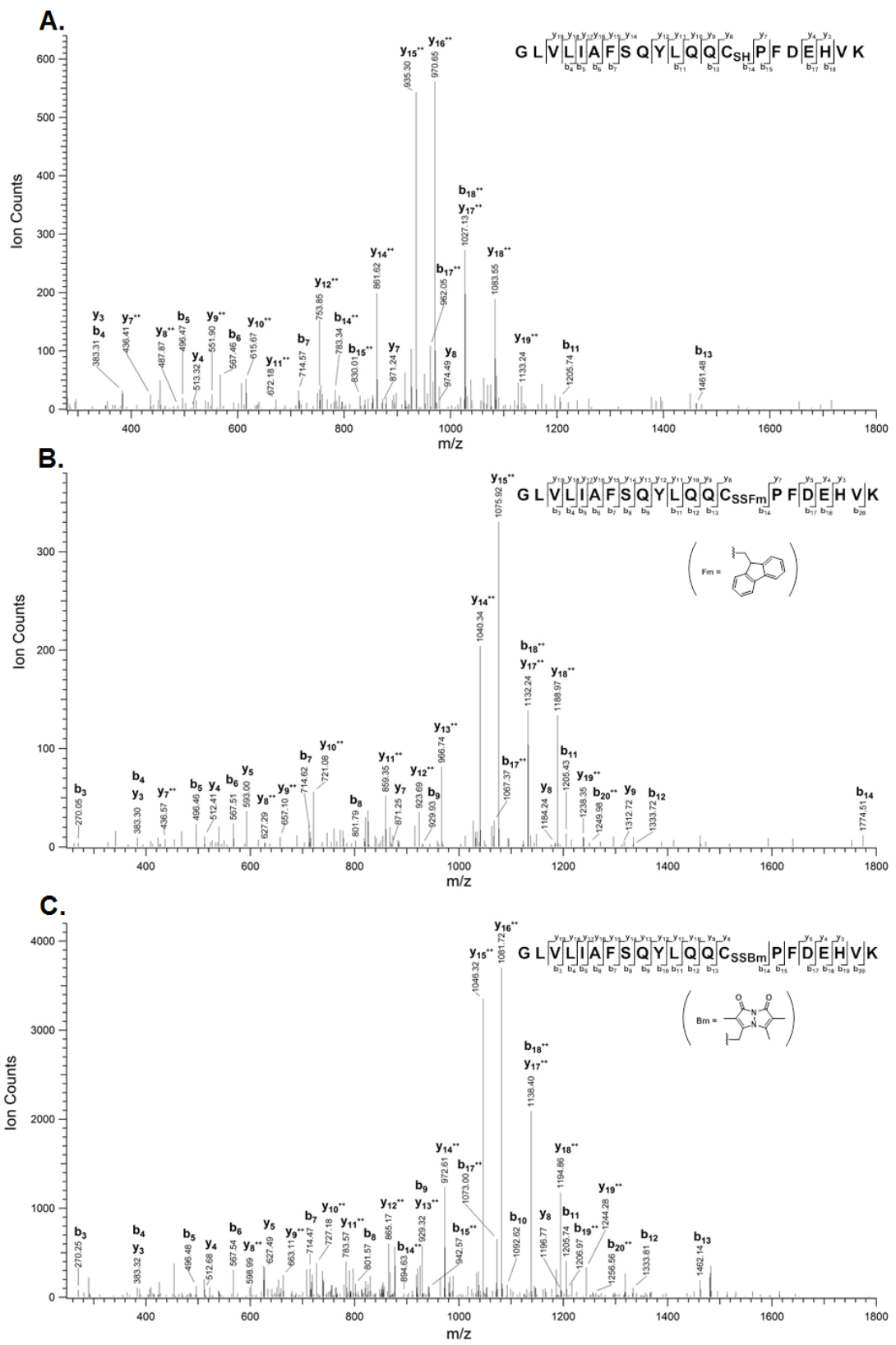

Figure S2. MS/MS analysis for selected tryptic-digested peptides from unlabeled and labeled BSA samples. (A) An unlabeled peptide: GLVLIAFSQYLQQCPFDEHVK. (B) A peptide labeled with FmSSPy-A: GLVLIAFSQYLQQC[SFm]PFDEHVK. (C) A peptide labeled with monobromobimane: GLVLIAFSQYLQQC[SSBm]PFDEHVK. 
Table S1. Conversion of BSA cysteines from PSSFm to PSSBm.

\begin{tabular}{|c|c|c|c|c|c|c|}
\hline group & peptide $^{\mathrm{a}}$ & Cys site & $\mathbf{m} / \mathbf{z}^{\mathbf{b}}$ & $\mathbf{e}$ & peak area ${ }^{c}$ & conversion $(\%)^{d}$ \\
\hline \multirow[t]{2}{*}{1} & SLHTLFGDELC+222.046K & Cys99 & 792.86 & 2 & $2.07 \mathrm{E}+09$ & 4.8 \\
\hline & SLHTLFGDELC $+210.050 \mathrm{~K}$ & Cys99 & 786.86 & 2 & $4.08 \mathrm{E}+10$ & \\
\hline \multirow[t]{2}{*}{2} & GLVLIAFSQYLQQC+222.046PFDEHVK & Cys58 & 886.43 & 3 & $1.35 \mathrm{E}+09$ & 71.2 \\
\hline & GLVLIAFSQYLQQC+210.050PFDEHVK & Cys58 & 882.44 & 3 & $5.46 \mathrm{E}+08$ & \\
\hline \multirow[t]{2}{*}{3} & LFTFHADIC+222.046TLPDTEK & Cys537 & 1036.98 & 2 & $2.90 \mathrm{E}+08$ & 2.4 \\
\hline & LFTFHADIC+210.050TLPDTEK & Cys537 & 1030.98 & 2 & $1.16 \mathrm{E}+10$ & \\
\hline \multirow[t]{2}{*}{4} & HADIC+222.046TLPDTEK & Cys537 & 782.84 & 2 & $7.22 \mathrm{E}+07$ & 9.2 \\
\hline & HADIC+210.050TLPDTEK & Cys537 & 776.84 & 2 & $7.16 \mathrm{E}+08$ & \\
\hline \multirow[t]{2}{*}{5} & MPC+222.046TEDYLSLILNR & Cys471 & 945.43 & 2 & $4.93 \mathrm{E}+08$ & 22.9 \\
\hline & MPC+210.050TEDYLSLILNR & Cys471 & 939.44 & 2 & $1.66 \mathrm{E}+09$ & \\
\hline \multirow[t]{2}{*}{6} & YIC+222.046DNQDTISSK & Cys288 & 804.84 & 2 & $1.68 \mathrm{E}+09$ & 10.3 \\
\hline & YIC+210.050DNQDTISSK & Cys288 & 798.84 & 2 & $1.46 \mathrm{E}+10$ & \\
\hline \multirow[t]{2}{*}{7} & LKPDPNTLC+222.046DEFK & Cys147 & 871.40 & 2 & $1.98 \mathrm{E}+09$ & 4.8 \\
\hline & LKPDPNTLC+210.050DEFK & Cys147 & 865.40 & 2 & $3.96 \mathrm{E}+10$ & \\
\hline \multirow[t]{2}{*}{8} & QEPERNEC+222.046FLSHK & Cys 125 & 919.90 & 2 & $1.51 \mathrm{E}+07$ & 10.7 \\
\hline & QEPERNEC $+210.050 \mathrm{FLSHK}$ & Cys 125 & 913.90 & 2 & $1.26 \mathrm{E}+08$ & \\
\hline \multirow[t]{2}{*}{9} & DDPHAC+222.046YSTVFDK & Cys392 & 860.34 & 2 & $4.81 \mathrm{E}+08$ & 7.3 \\
\hline & DDPHAC+210.050YSTVFDK & Cys392 & 854.34 & 2 & $6.14 \mathrm{E}+09$ & \\
\hline \multirow[t]{2}{*}{10} & RPC+222.046FSALTPDETYVPK & Cys510 & 1023.48 & 2 & $4.87 \mathrm{E}+08$ & 3.4 \\
\hline & RPC+210.050FSALTPDETYVPK & Cys510 & 1017.48 & 2 & $1.38 \mathrm{E}+10$ & \\
\hline \multirow[t]{2}{*}{11} & SHC+222.046IAEVEK & Cys 312 & 619.27 & 2 & $1.39 \mathrm{E}+09$ & 6.2 \\
\hline & SHC+210.050IAEVEK & Cys 312 & 613.27 & 2 & $2.11 \mathrm{E}+10$ & \\
\hline \multirow[t]{2}{*}{12} & $\mathrm{C}+222.046 \mathrm{C}+210.050 \mathrm{TESLVNR}$ & Cys499 & 728.78 & 2 & $5.85 \mathrm{E}+07$ & 20.6 \\
\hline & $\mathrm{C}+210.050 \mathrm{C}+210.050 \mathrm{TESLVNR}$ & Cys499 & 722.78 & 2 & $2.25 \mathrm{E}+08$ & \\
\hline \multirow[t]{2}{*}{13} & PC+222.046FSALTPDETYVPK & Cys510 & 945.43 & 2 & $4.93 \mathrm{E}+08$ & 48.0 \\
\hline & PC+210.050FSALTPDETYVPK & Cys510 & 939.42 & 2 & $5.35 \mathrm{E}+08$ & \\
\hline
\end{tabular}

a. Labeled with monobromobimane [SSBm]: +222.046; labeled with FmSSPy-A [SFm]: +210.050.

b. The $\mathrm{m} / \mathrm{z}$ value of parent ion for peptides.

c. Peak area of peptide ions in selective extracted ion chromatogram.

d. Conversion $(\%)=$ Peak area $($ Peptide[SSBm] $) /($ Peak area $($ Peptide $[\mathrm{SSBm}])+$ Peak area (Peptide[SFm]).

The labeling reaction was carried out at protein level, followed by tryptic digestion and LC-MS/MS analysis. The peak area of peptide in exacted ion chromatogram was used for quantification. BSA sequence includes a 24-AA length signal fragment. Therefore, Cys34 mentioned in the text is Cys58 in this table. 


\section{Labeling of a specific site (Cys34) on non-reduced BSA}

Procedure of BSA gel-filtrations:

Bovine serum albumin (BSA) was purchased from Aldrich and used as received. For the gel-filtration (size exclusion), Sephadex G25 pre-packed in PD-10 columns was purchased from General Electronics. Before loading of samples, the column was first equilibrated with $20 \mathrm{mM}$ PBS (pH 7.4, $3.5 \mathrm{~mL} \times 4$ ). 2.5 $\mathrm{mL}$ of reaction solution was loaded on the column, eluted by gravity and discarded. Then $3.5 \mathrm{~mL}$ of buffer solution was added and samples were collected in separate new vials. The collected solutions were directly used for MS analysis.

\section{BSA[Cys34] modification with FmSSPy-A and IAM:}

To $5.05 \mathrm{mg}$ of BSA dissolved in $2 \mathrm{~mL}$ of sodium phosphate buffer $(100 \mathrm{mM}$, pH 7.1) was added 5 equiv $(19 \mu \mathrm{L})$ of FmSSPy-A in DMF (20 mM stock solution) at room temperature. The mixture was stirred for $1 \mathrm{~h}$. The volume of the solution was adjusted to $2.5 \mathrm{~mL}$ with the same buffer solution then it was directly loaded to an equilibrated PD-10 column. After draining the solution by gravity, $3.5 \mathrm{~mL}$ of buffer was added to elute the desired protein in a new vial. To the eluent was added $152 \mu \mathrm{L}$ of iodoacetamide (IAM, $50 \mathrm{mM}$ stock solution in DMF) followed by $304 \mu \mathrm{L}$ of DBU (in $25 \mathrm{mM}$ stock solution in DMF). The mixture was stirred for $1 \mathrm{~h}$. Then $2.5 \mathrm{~mL}$ of the solution was loaded to a pre-equilibrated PD-10 column and drained. The protein sample was collected by elution of $3.5 \mathrm{~mL}$ of buffer. The eluent was directly used for the trypsin digestion and subjected to LC-MS/MS analysis.

\section{High resolution nano-HPLC tandem mass spectrometry analysis:}

The peptide samples were subjected to Thermo Scientific ${ }^{\mathrm{TM}}$ Orbitrap Fusion ${ }^{\mathrm{TM}}$ Tribrid $^{\mathrm{TM}}$ with an Easy$\mathrm{nLC}^{\mathrm{TM}} 1000$ ultra-high pressure LC on a Thermo Scientific ${ }^{\mathrm{TM}}$ PepMap $100 \mathrm{C} 18$ column $(2 \mu \mathrm{m}, 50 \mu \mathrm{m} \mathrm{x}$ $15 \mathrm{~cm}$ ). The peptides were separated over $115 \mathrm{~min}$ gradient eluted at $300 \mathrm{~nL} / \mathrm{min}$ with $0.1 \%$ formic acid (FA) in water (solvent $\mathrm{A}$ ) and $0.1 \% \mathrm{FA}$ in acetonitrile (solvent B) (5-35\% B in $85 \mathrm{~min}$, followed by 35 $50 \% \mathrm{~B}$ over $10 \mathrm{~min}$ and 50-95\% B over $10 \mathrm{~min}$ ). The run was completed by holding a $95 \% \mathrm{~B}$ for $10 \mathrm{~min}$. MS1 data was acquired on an Orbitrap Fusion mass spectrometry using a full scan method according to the following parameters: scan range 400-1500 m/z, Orbitrap resolution 120,000; AGC target 400,000; and maximum injection time of $50 \mathrm{~ms}$. MS2 data were collected using the following parameters: rapid scan rate, $\mathrm{HCD}$ collision energy 35\%, $1.6 \mathrm{~m} / \mathrm{z}$ isolation window, AGC 2,000 and maximum injection time of $50 \mathrm{~ms}$. MS2 precursors were selected for a $3 \mathrm{~s}$ cycle. The precursors with an assigned monoisotopic $\mathrm{m} / \mathrm{z}$ and a charge state of 2-7 were interrogated. The precursors were filtered using a $60 \mathrm{~s}$ dynamic exclusion window. 
A.

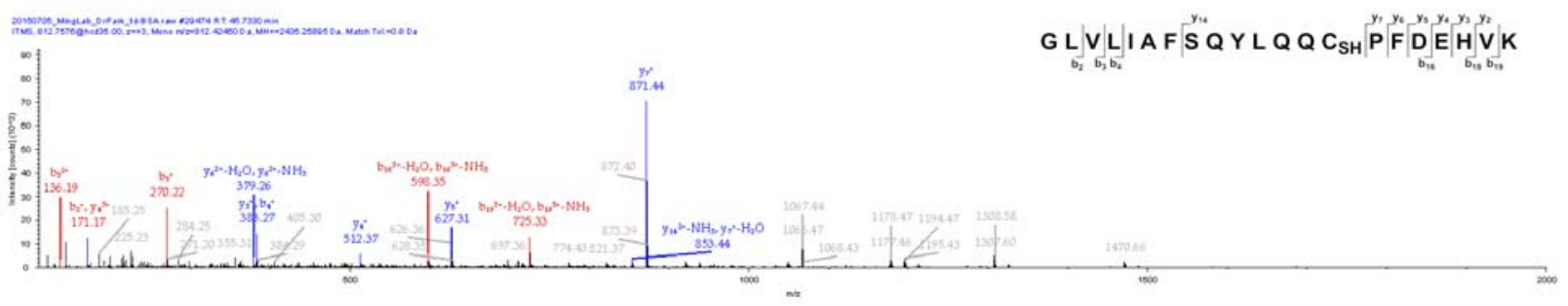

B.

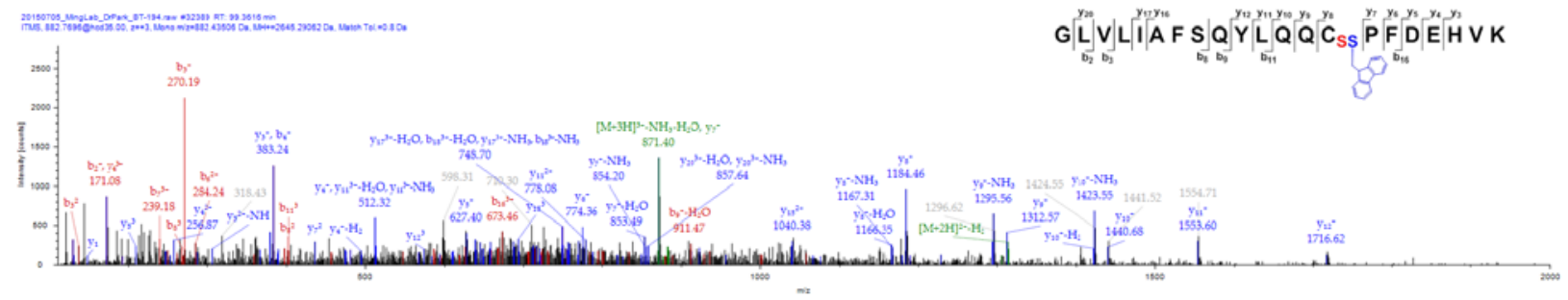

c.

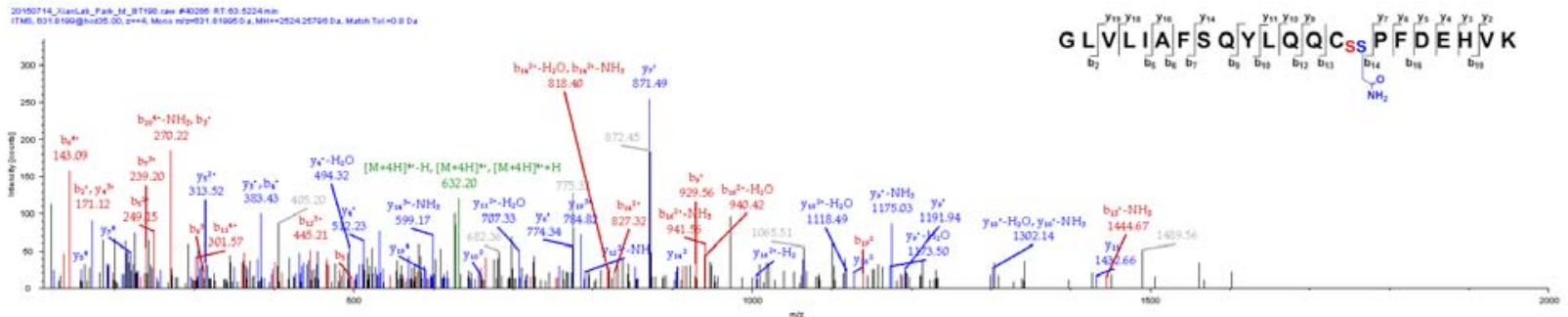

Figure S3. MS/MS analysis by Proteome Discoverer $^{\mathrm{TM}} 2.0$ of (A) peptide $\mathbf{1 4}$ (GLVLIAFSQYLQQCPFDEHVK), (B) peptide 16 (GLVLIAFSQYLQQC[SFm]PFDEHVK), (C) peptide 19 (GLVLIAFSQYLQQC[SS $\left.\left(\mathrm{CH}_{2} \mathrm{CONH}_{2}\right)\right]$ PFDEHVK). 


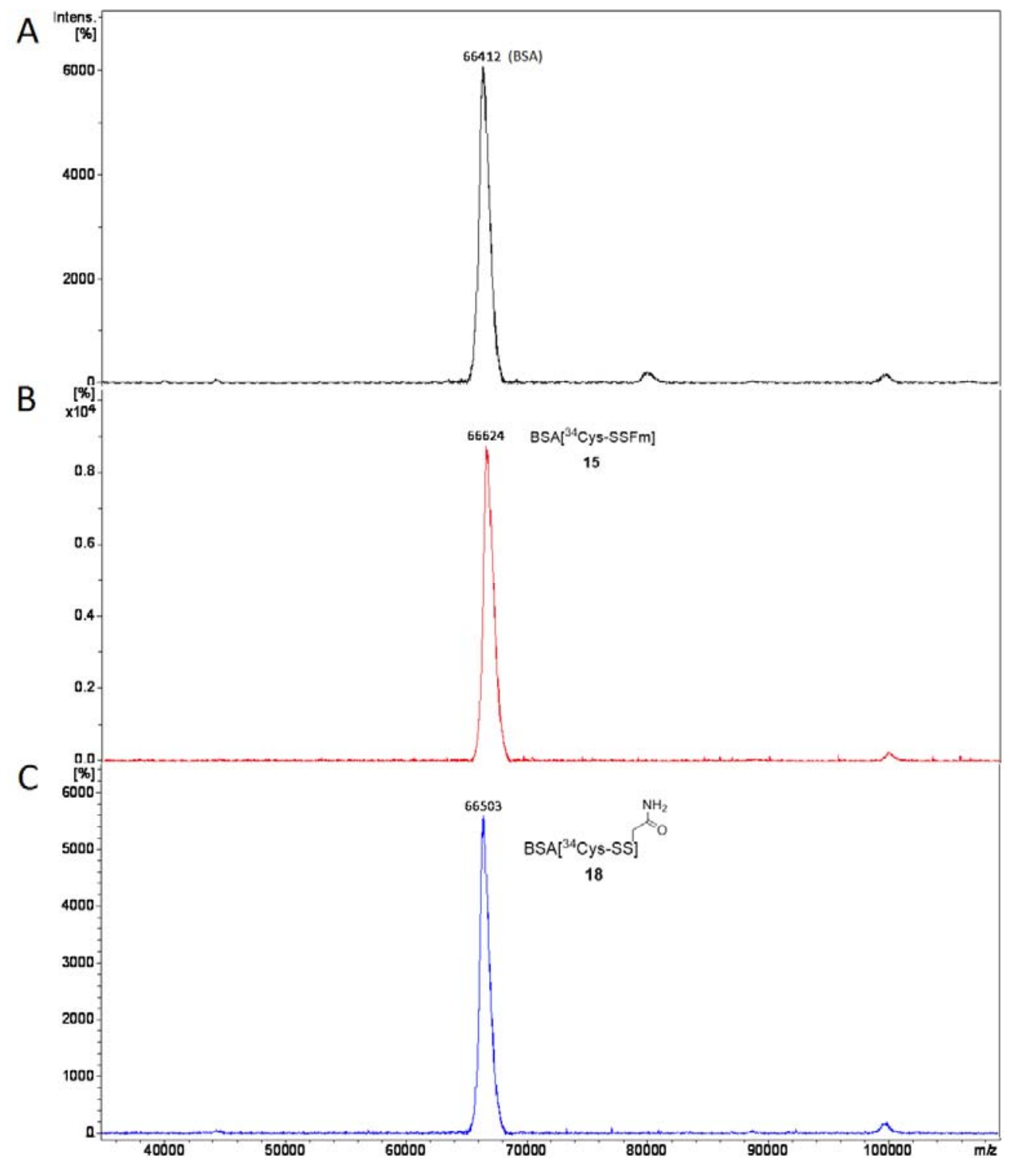

Figure S4. Intact BSA analysis by Maldi-TOF/TOF (Bruker UltrafleXtreme, Billerica, MA) of (A) nonreduced BSA, (B) BSA-SFm 15, (C) BSA-S $\left(\mathrm{CH}_{2} \mathrm{CONH}_{2}\right) 18$. 

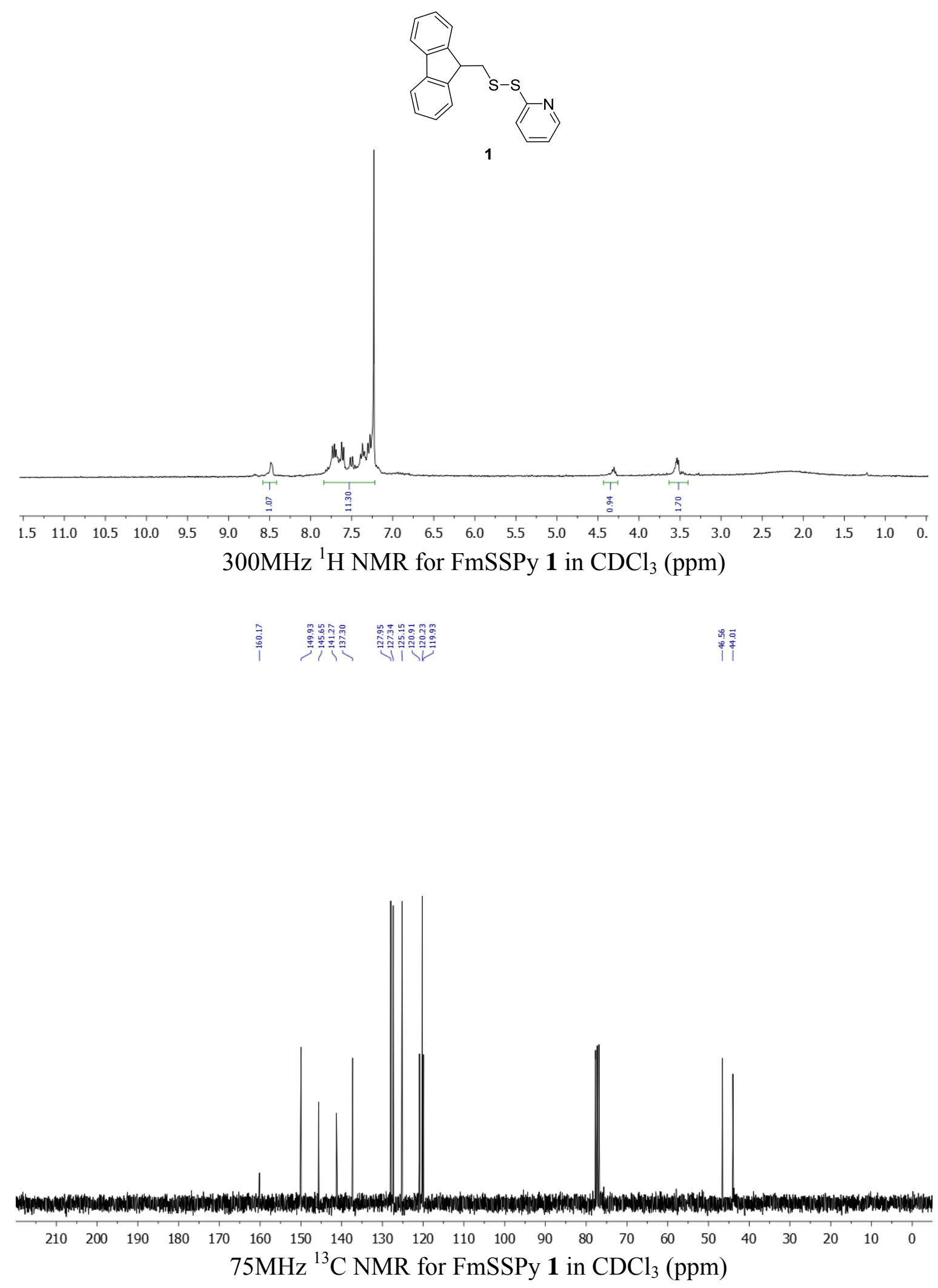


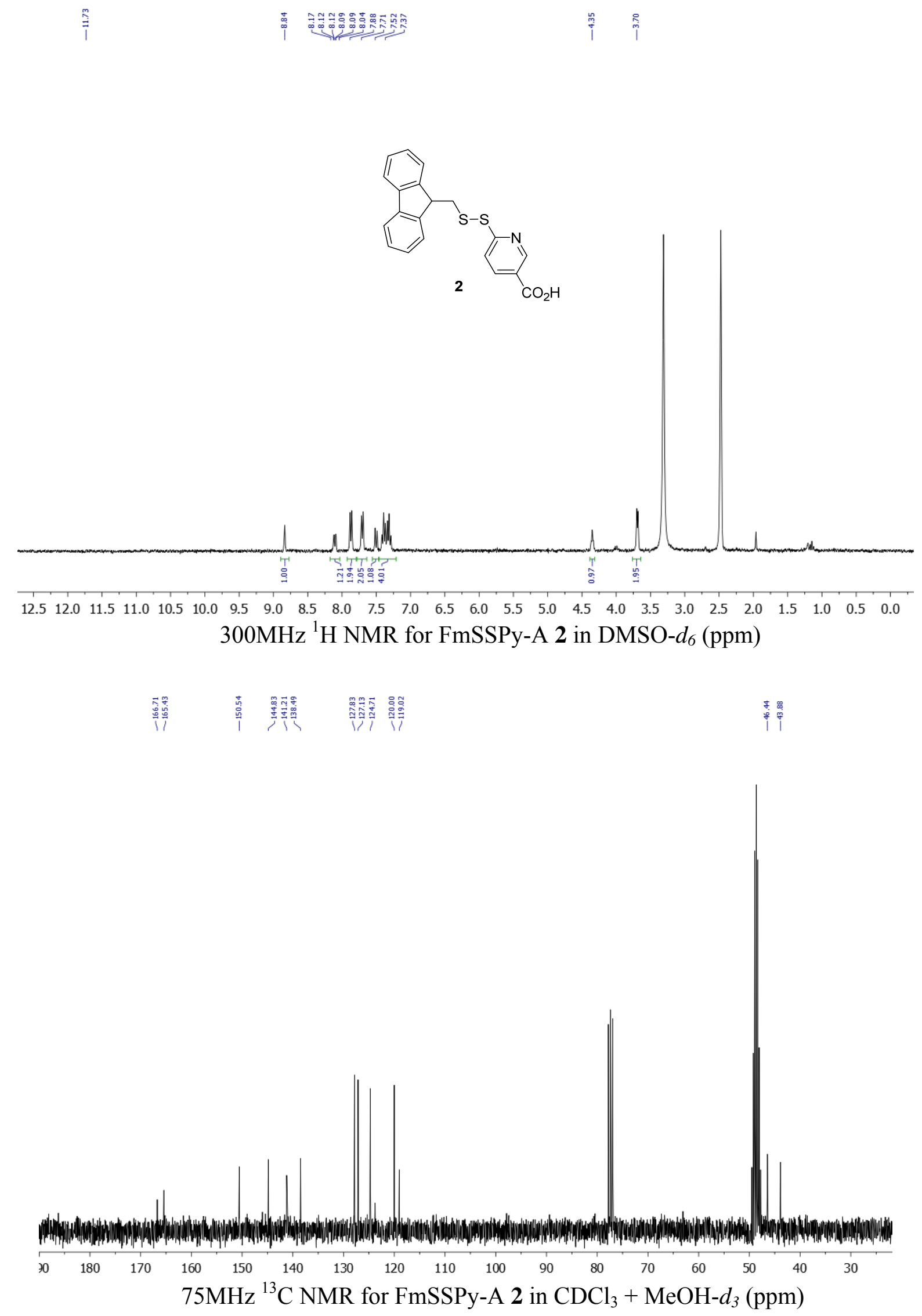



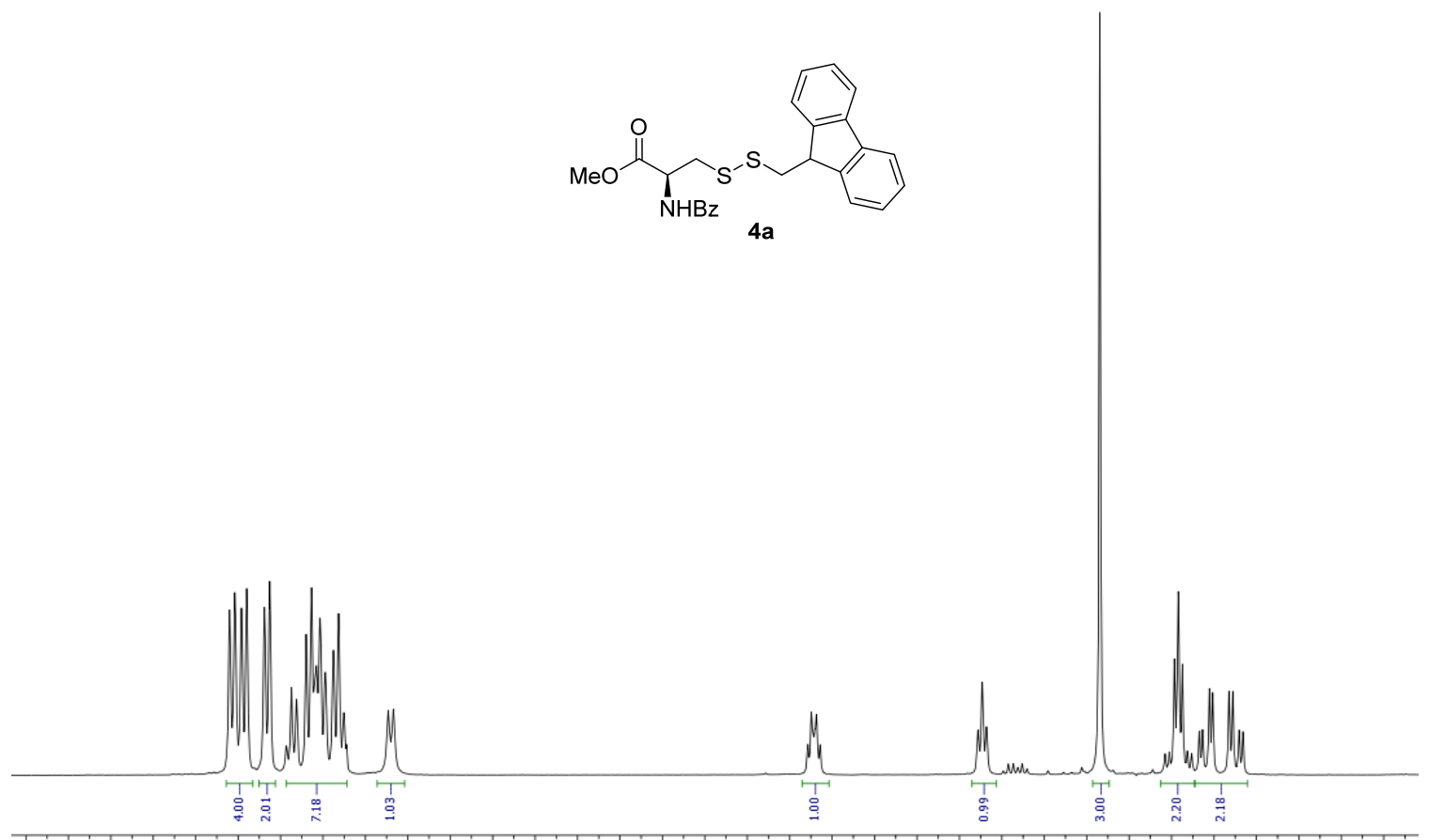

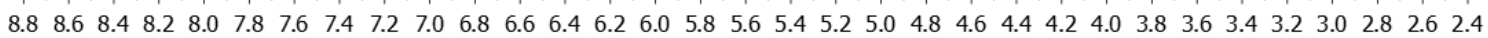
$300 \mathrm{MHz}{ }^{1} \mathrm{H}$ NMR for Bz-Cys[SSFm]-OMe 4a in $\mathrm{CDCl}_{3}$ (ppm)

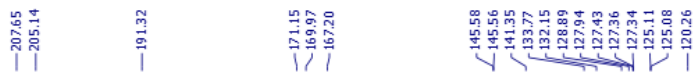

约 章

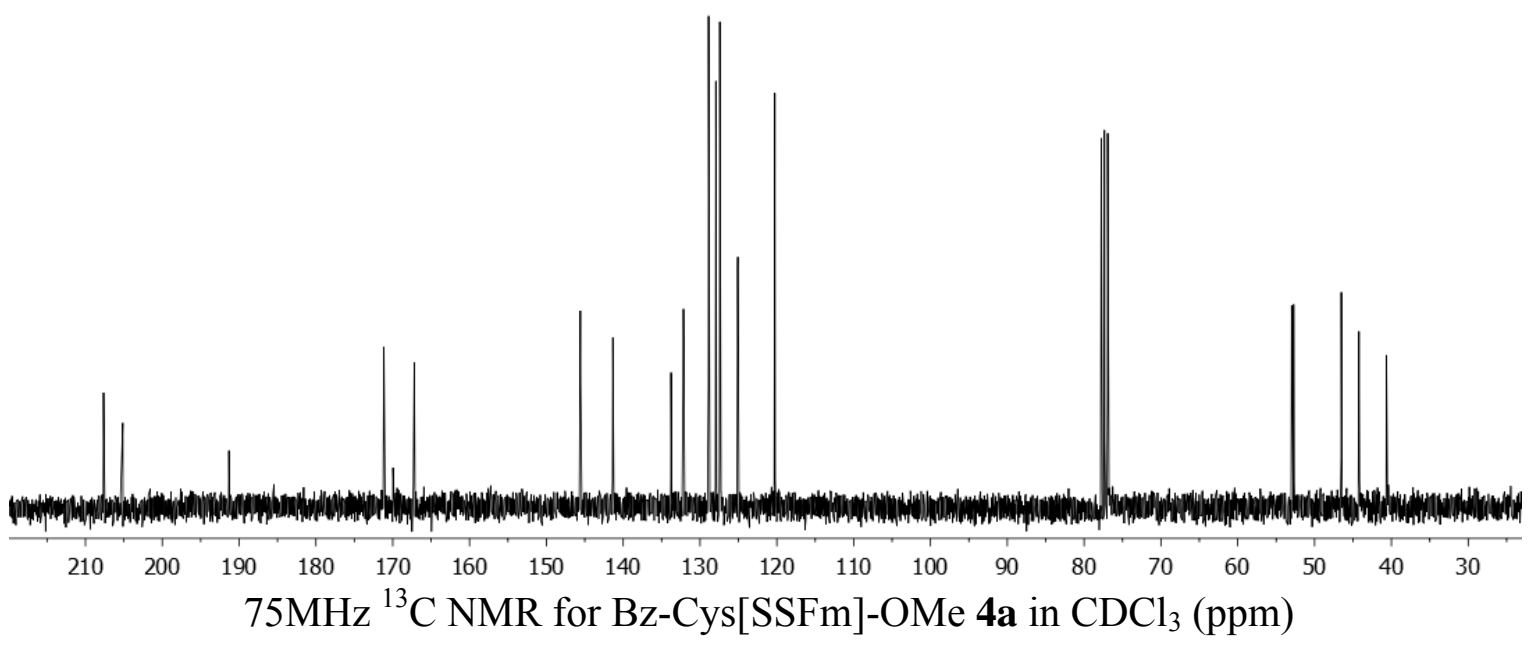



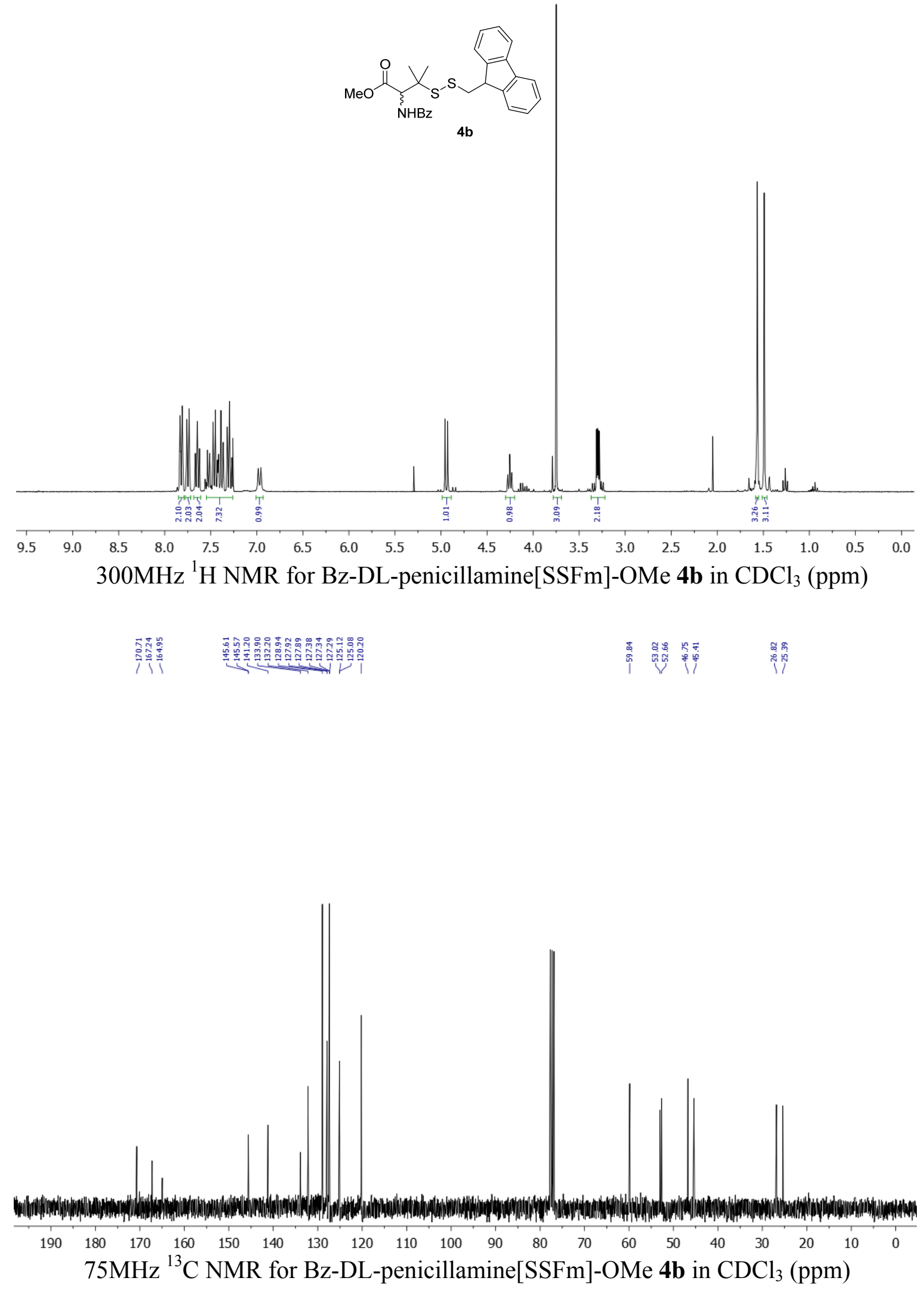

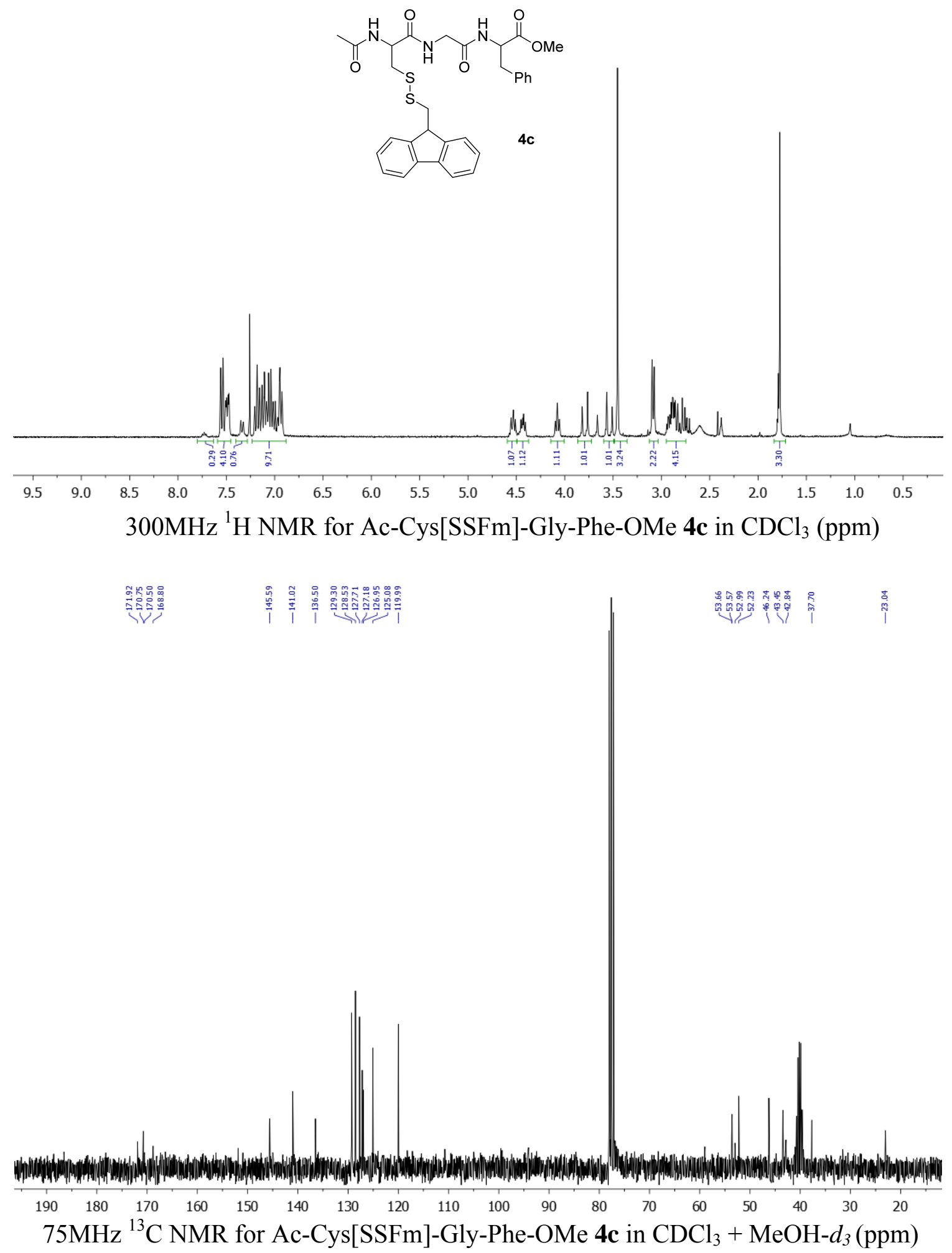

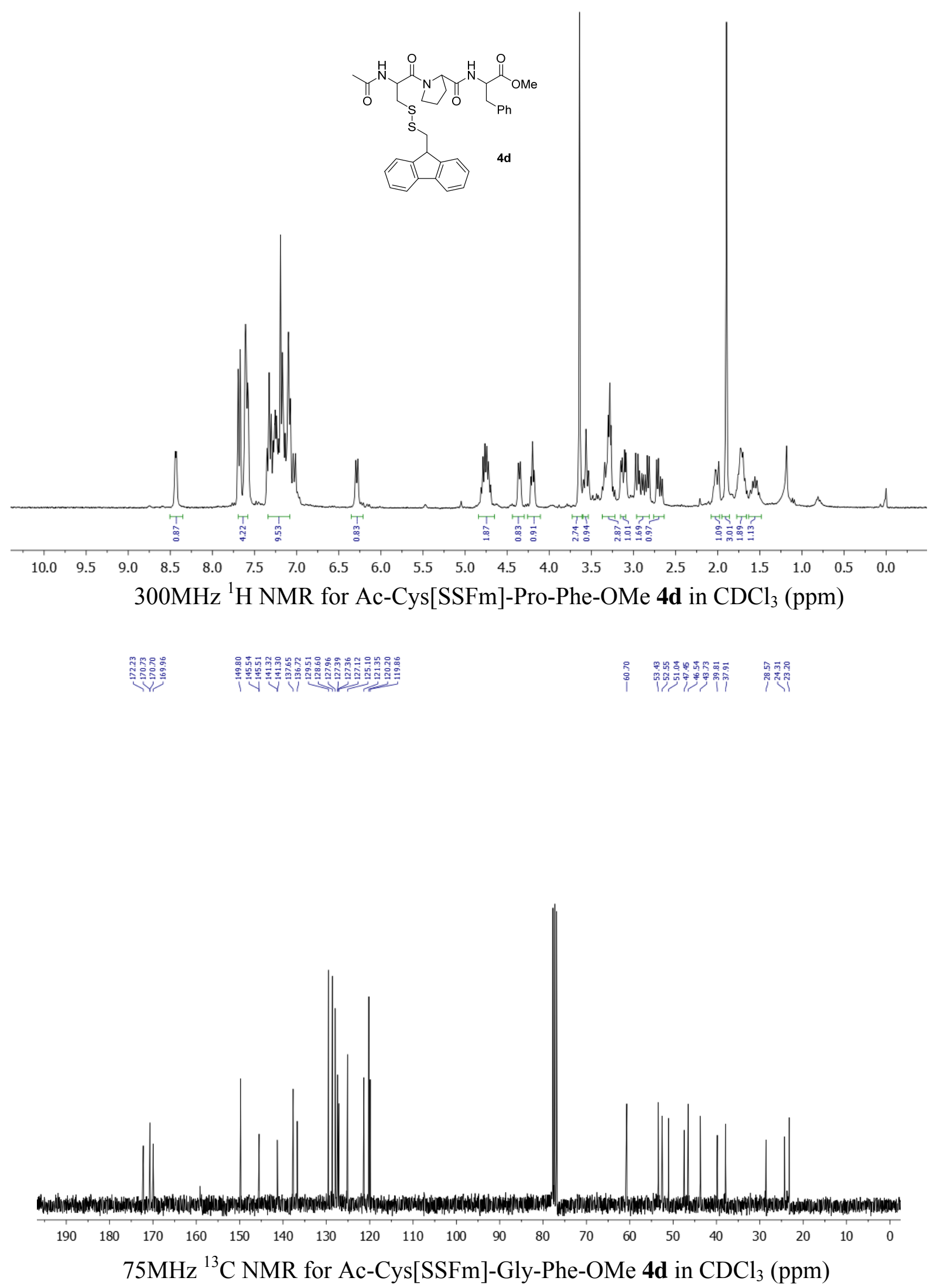


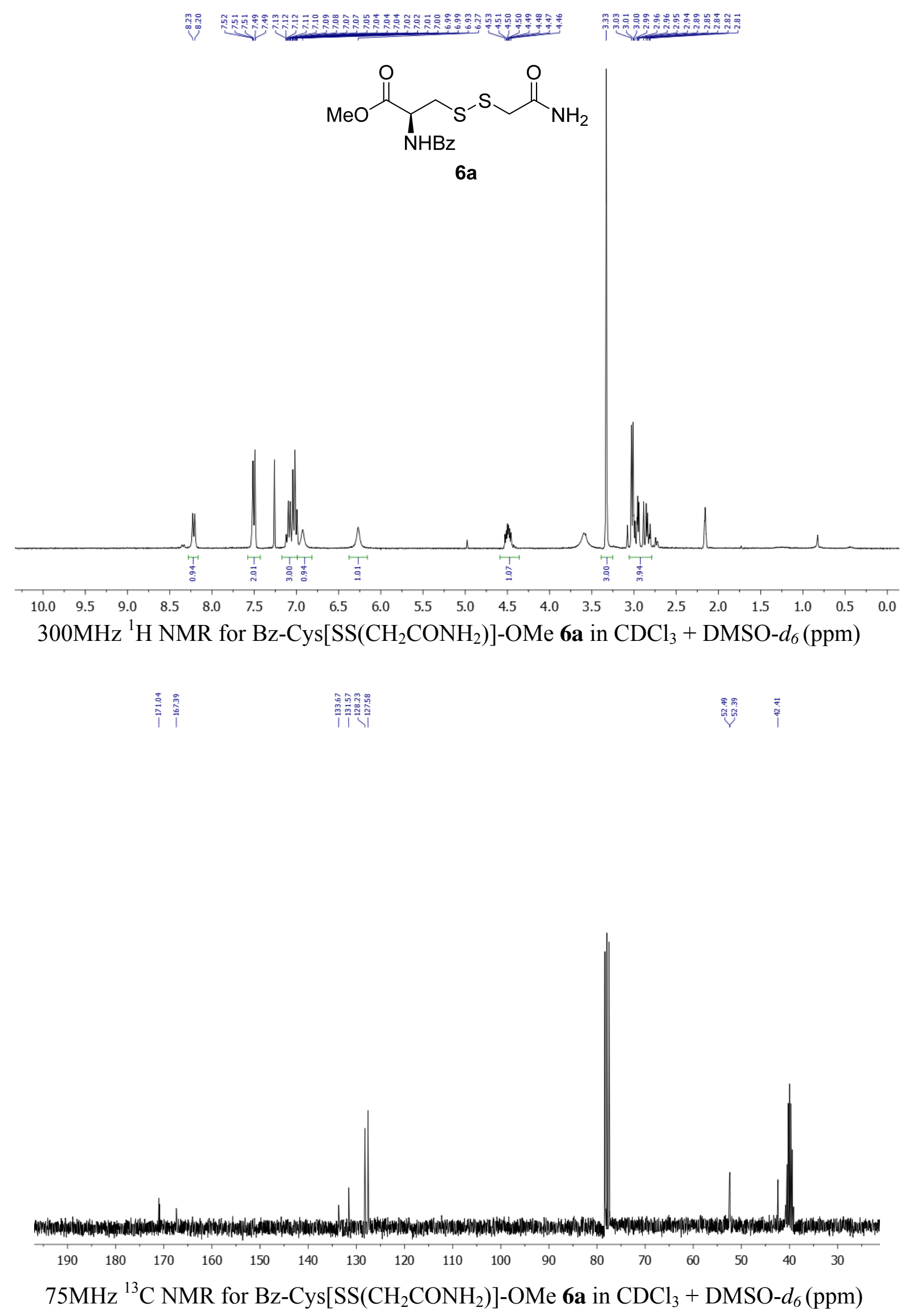




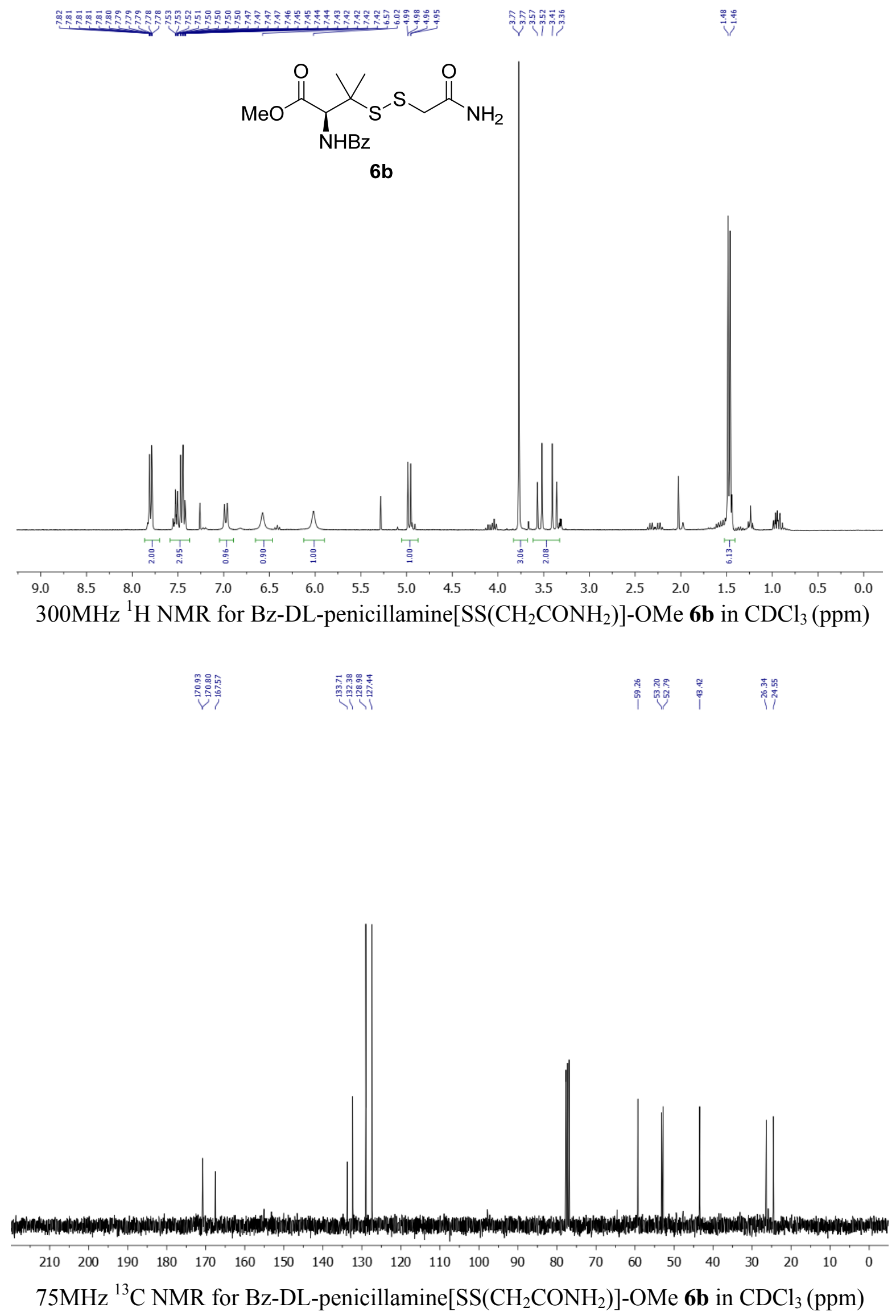



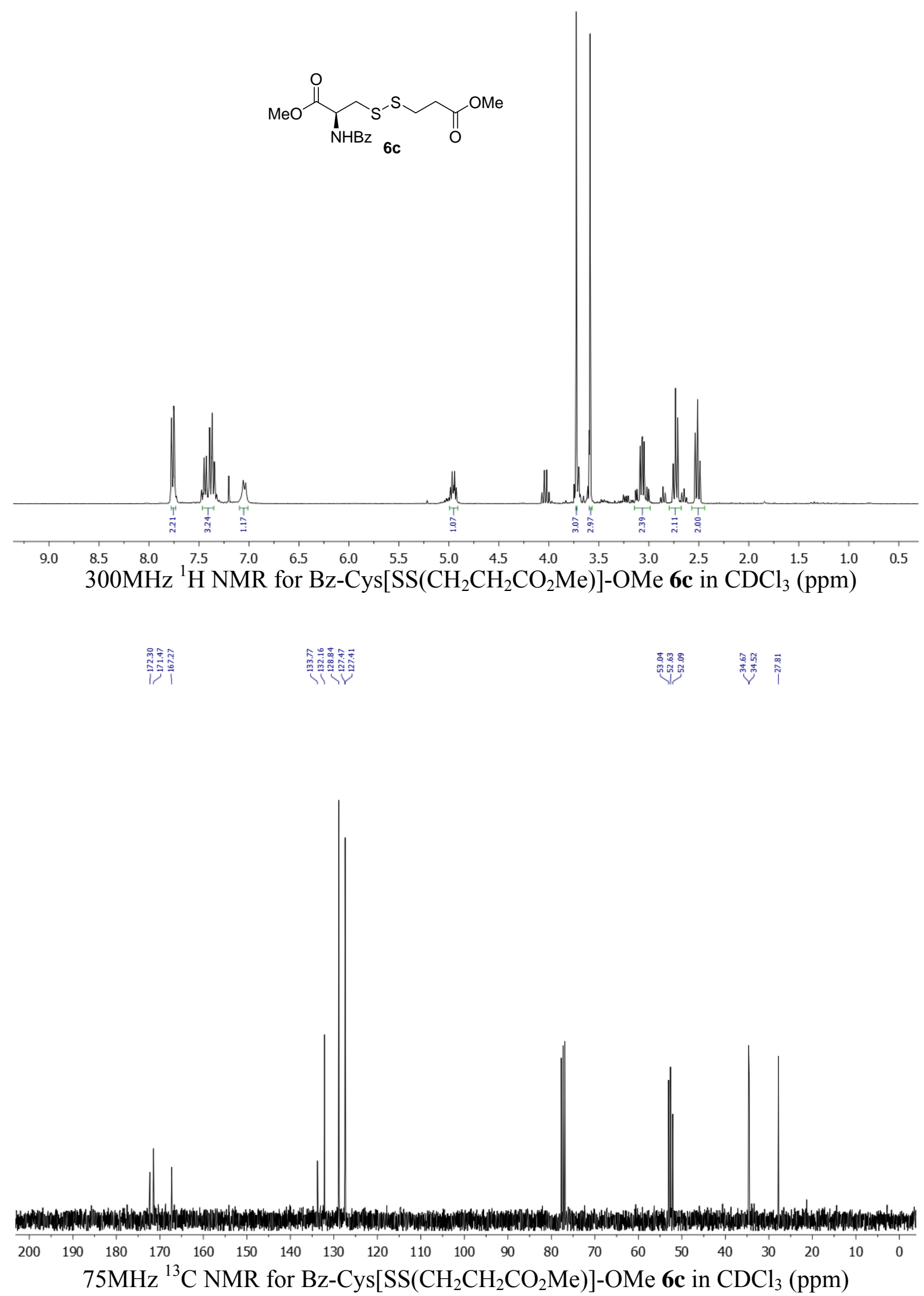


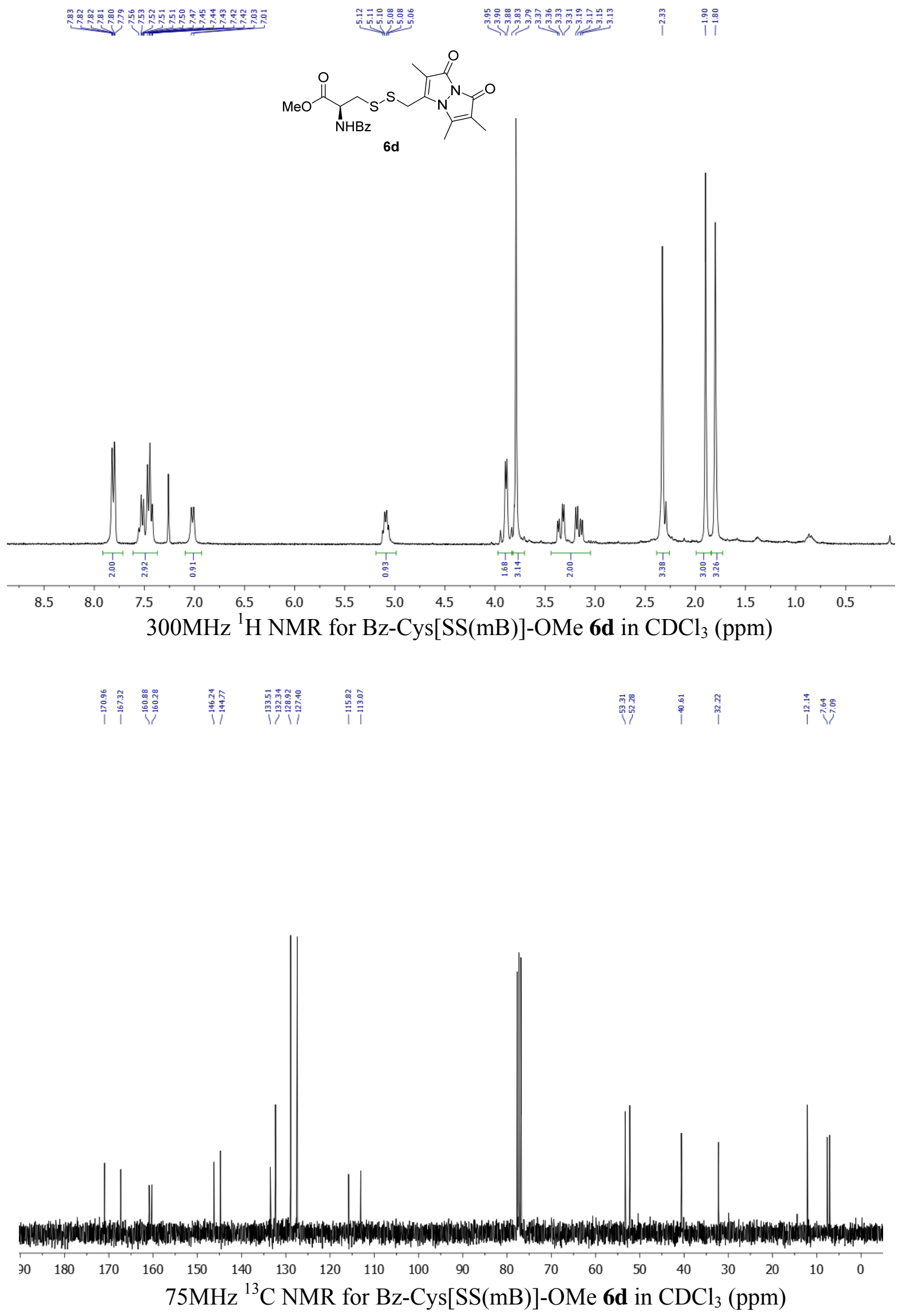



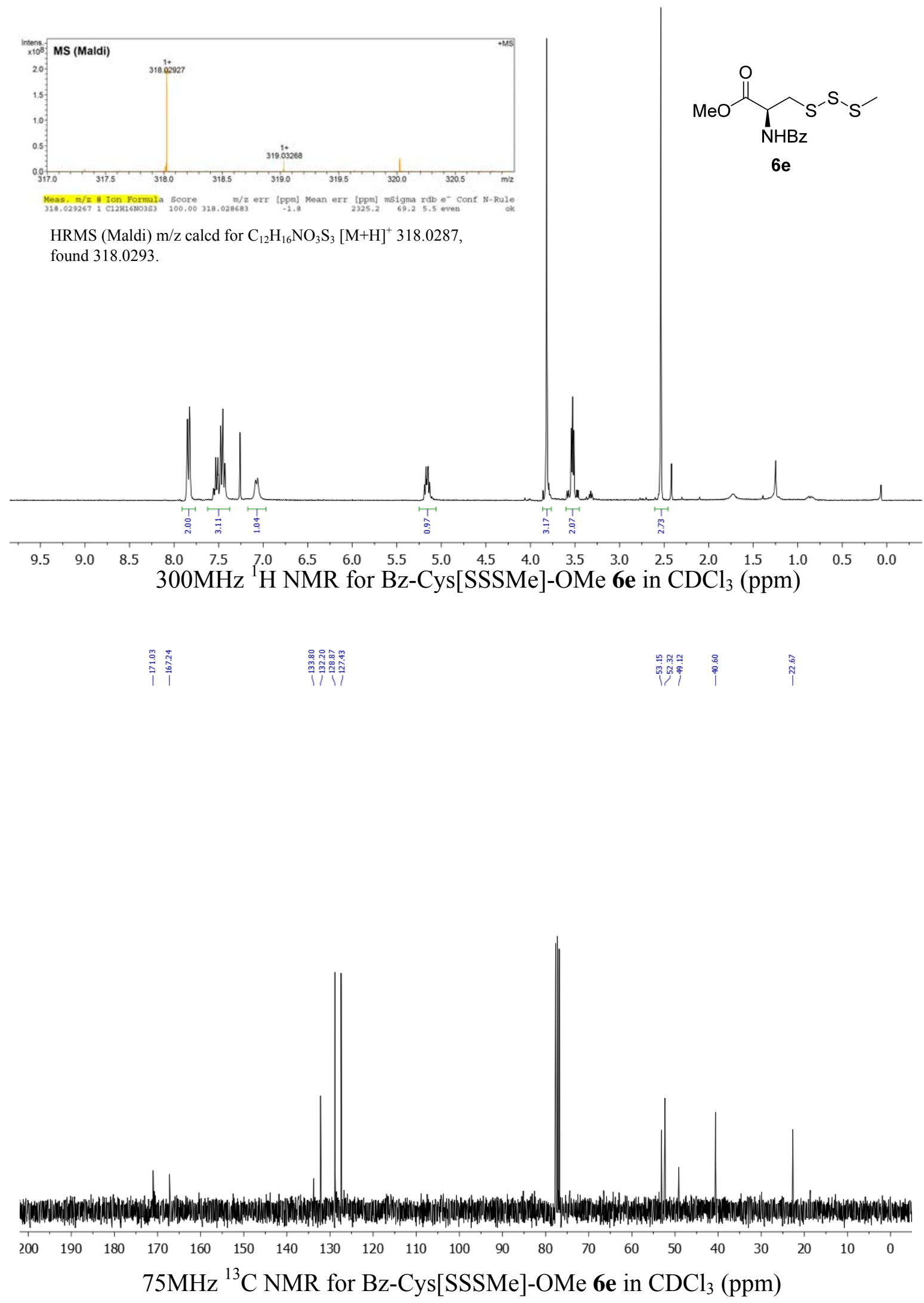
<smiles>COC(=O)CCSSC(C)(C)C(N)C(=O)OC</smiles>
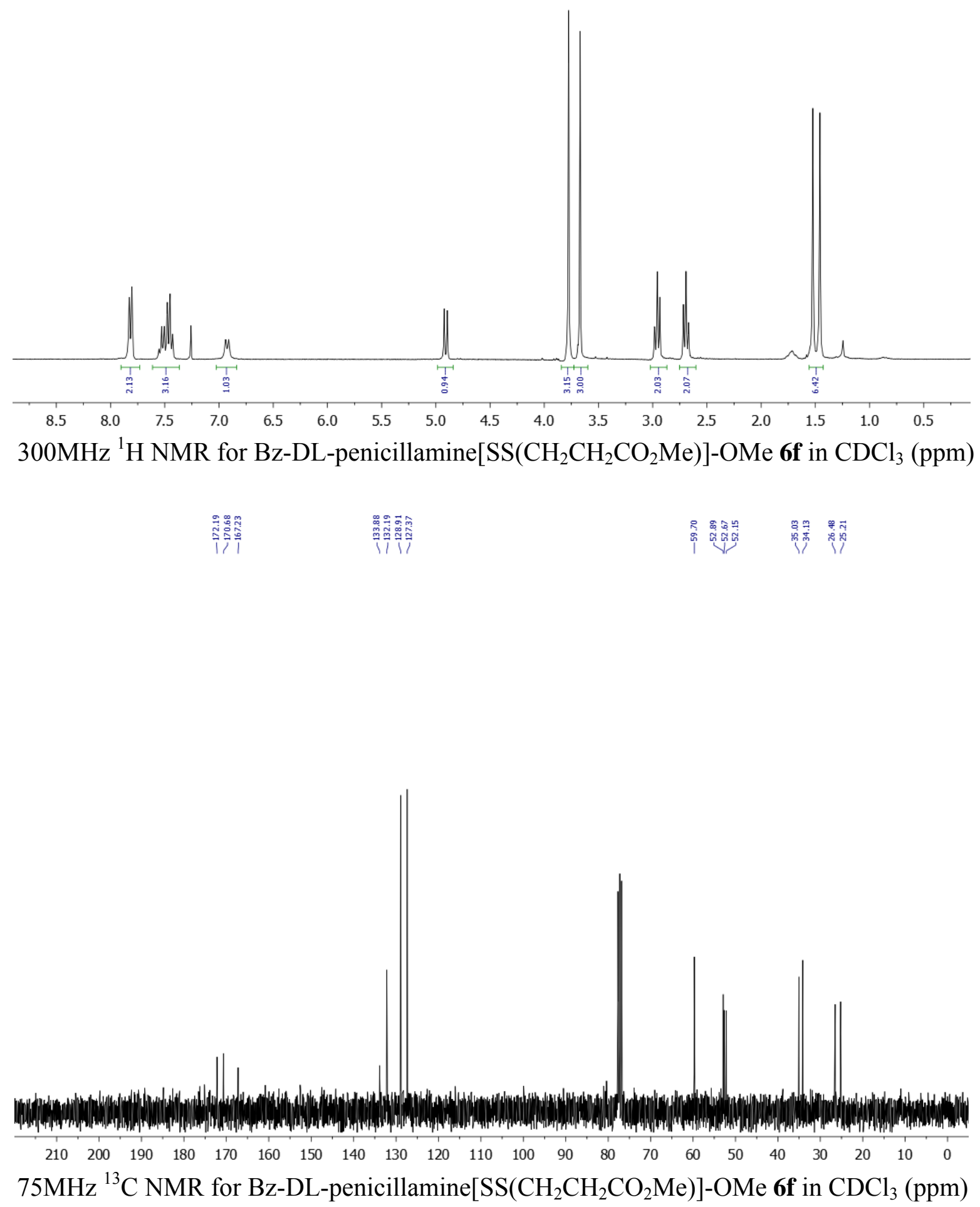

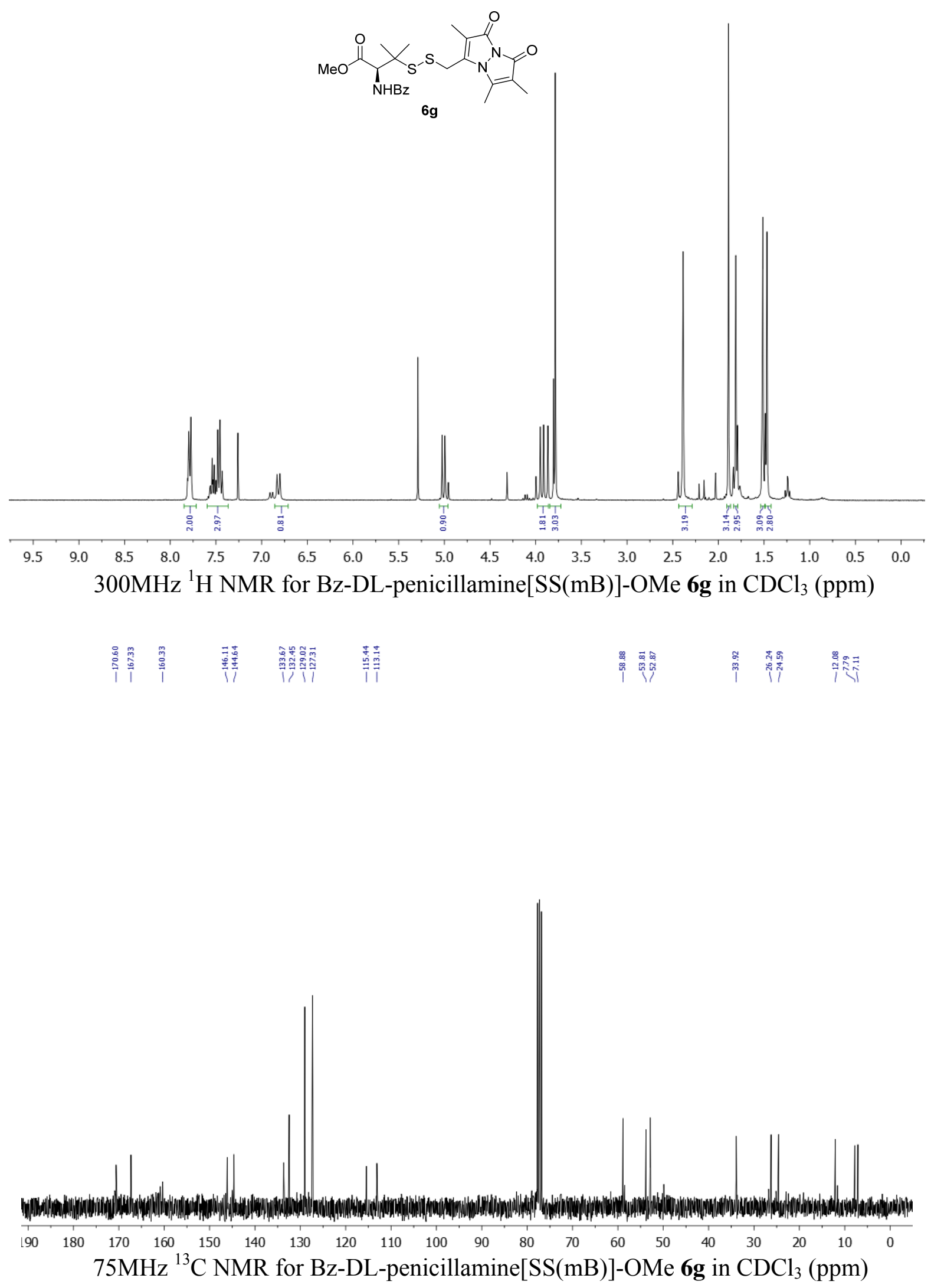

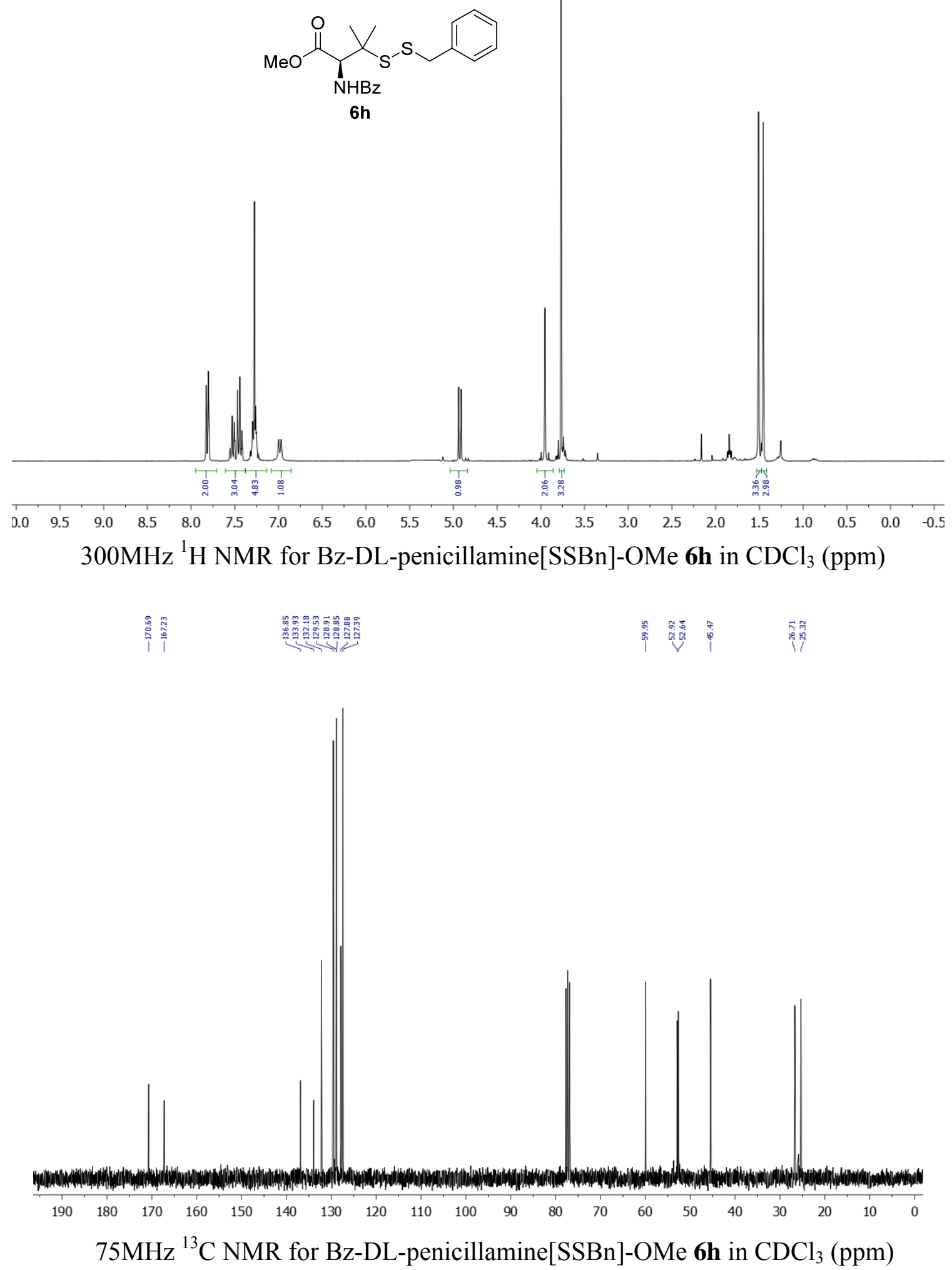


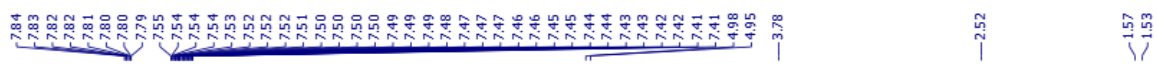<smiles>[R17]C(N)C(C(=O)OC)C(C)(C)SSSC</smiles>

$6 i$

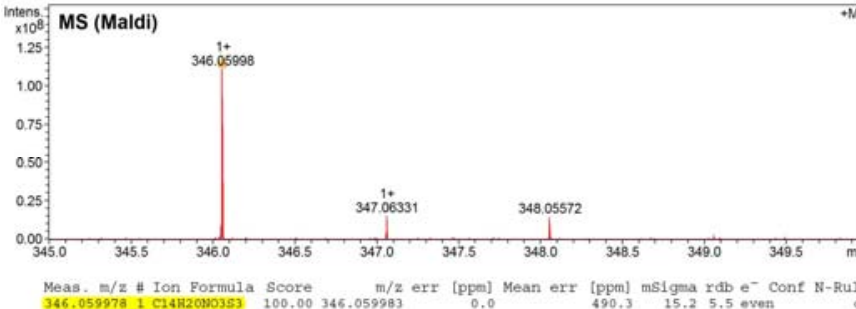

HRMS (Maldi) $\mathrm{m} / \mathrm{z}$ calcd for $\mathrm{C}_{14} \mathrm{H}_{20} \mathrm{NO}_{3} \mathrm{~S}_{3}[\mathrm{M}+\mathrm{H}]^{+} 346.0600$, found 346.0600 .
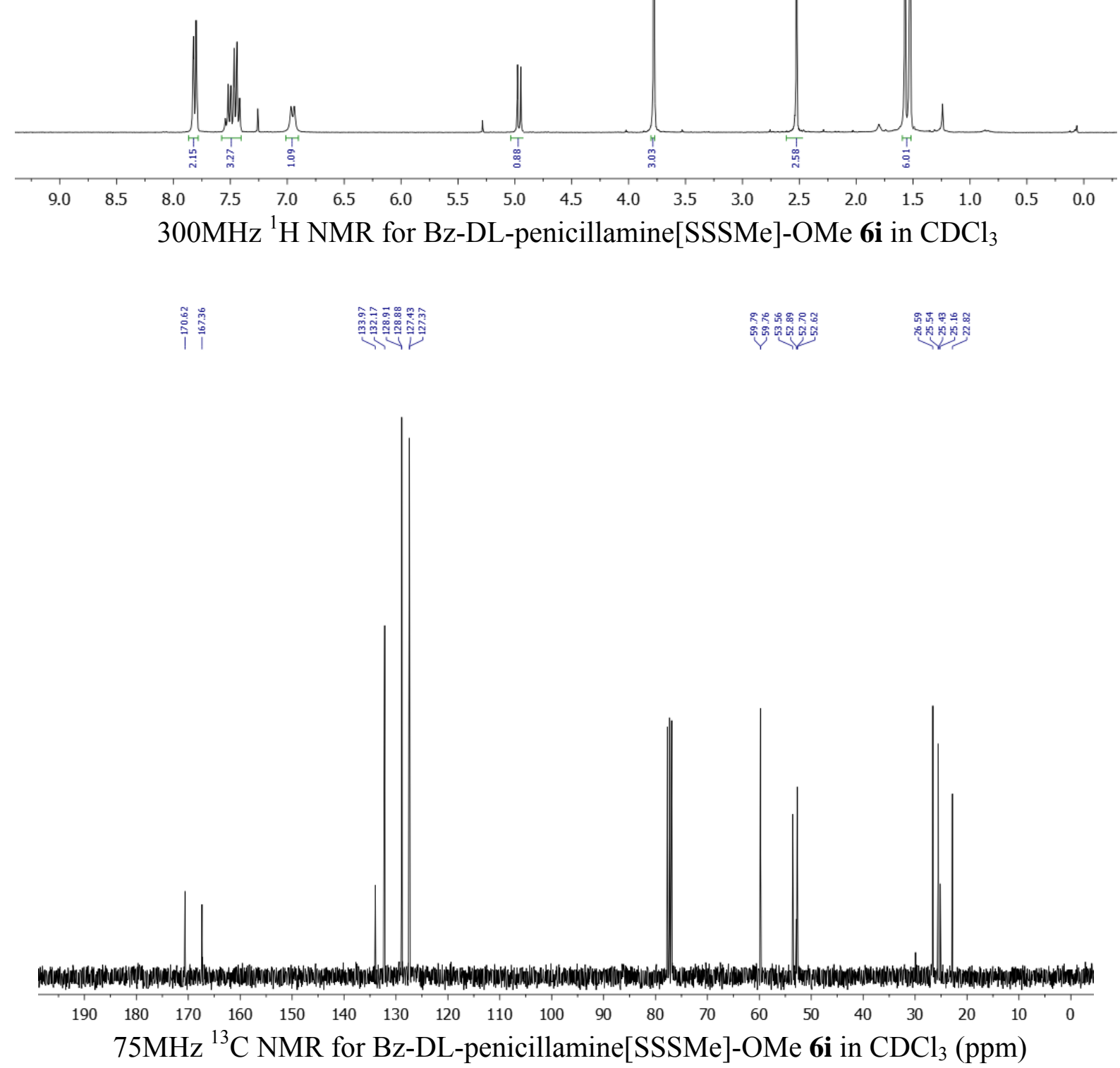

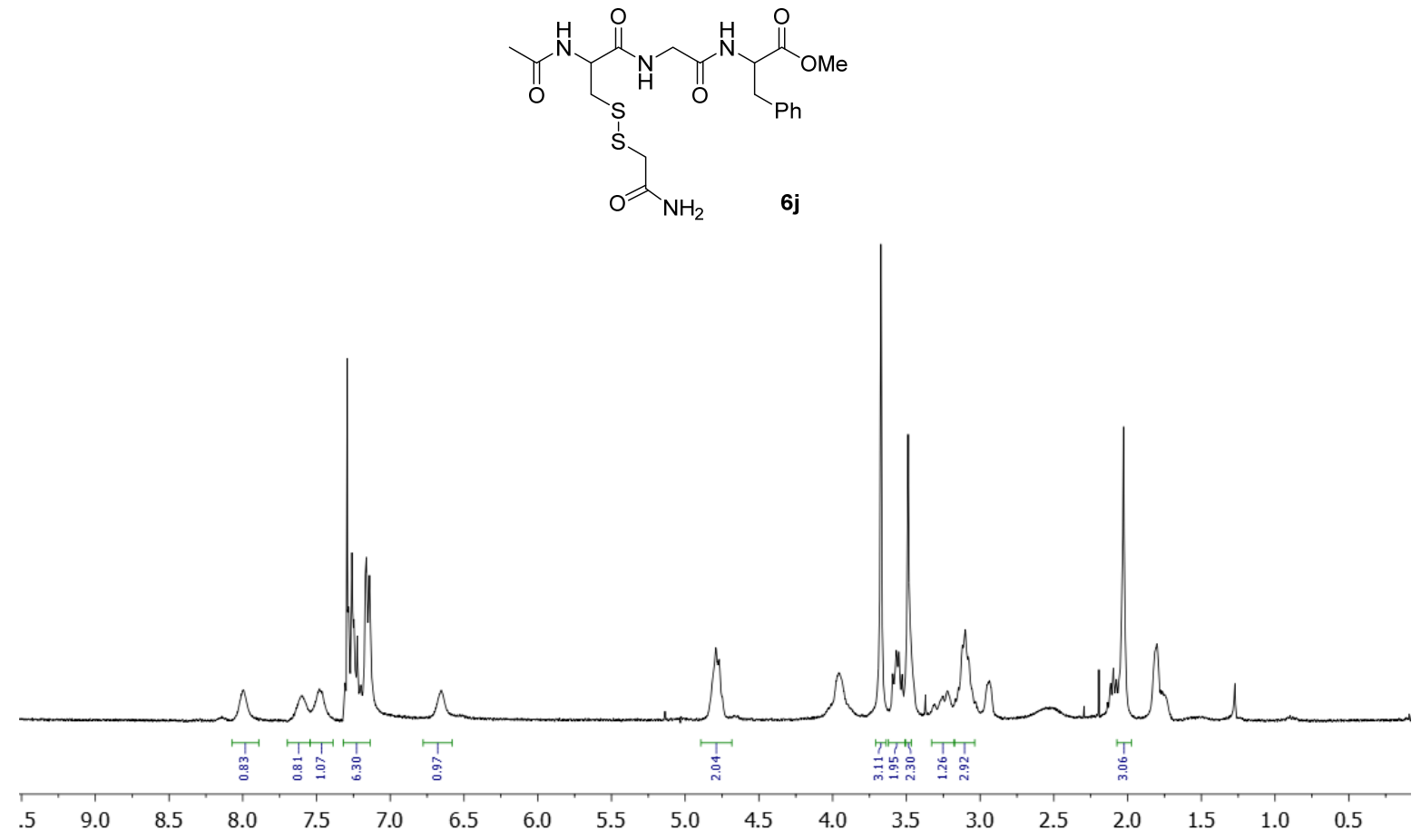

$300 \mathrm{MHz}{ }^{1} \mathrm{H}$ NMR for Ac-Cys[SS( $\left.\left.\mathrm{CH}_{2} \mathrm{CONH}_{2}\right)\right]$-Gly-Phe-OMe $\mathbf{6 j}$ in $\mathrm{CDCl}_{3}+\mathrm{DMSO}_{6}$ (ppm)

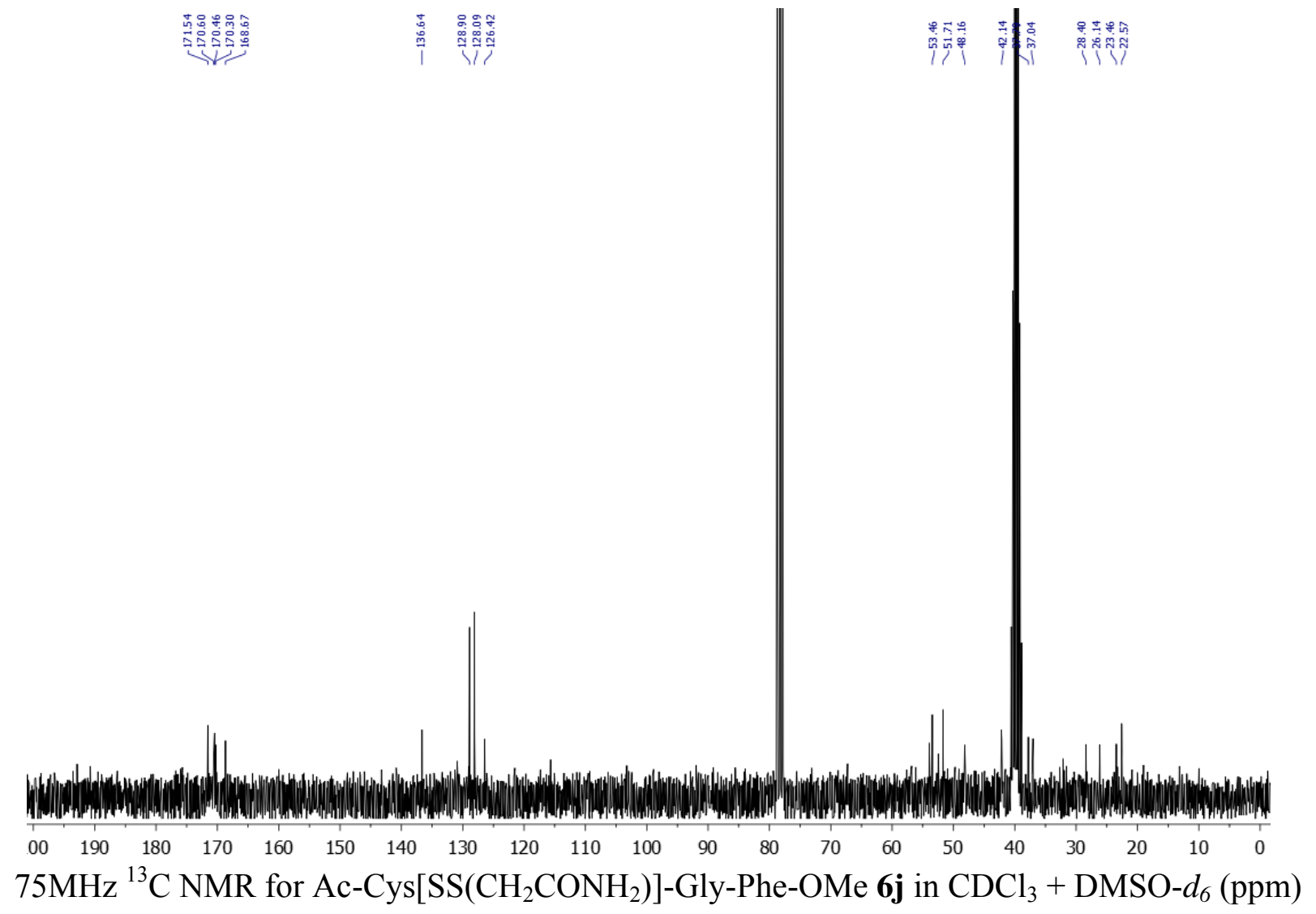



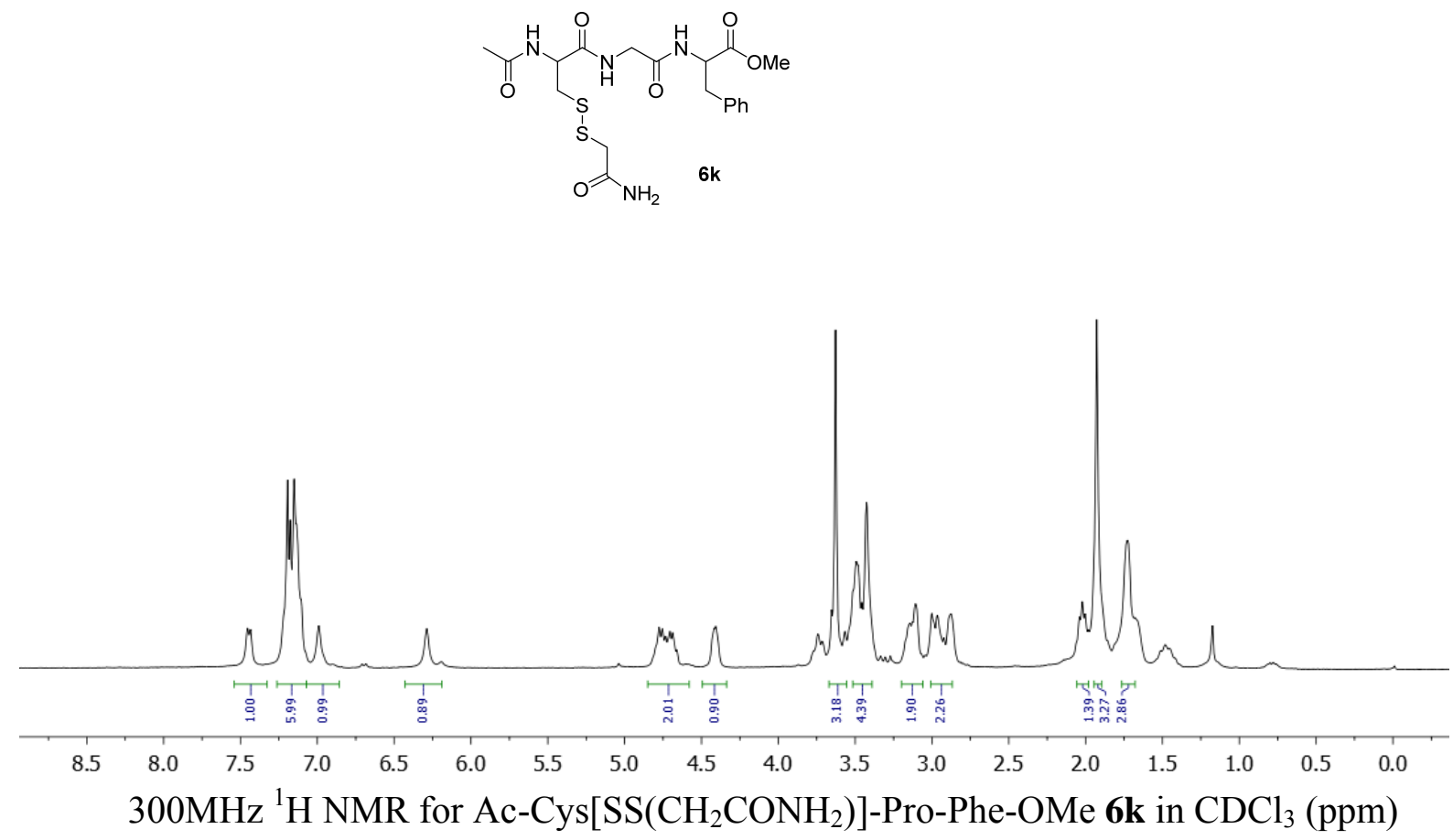

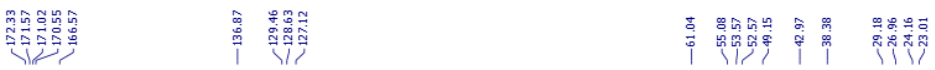

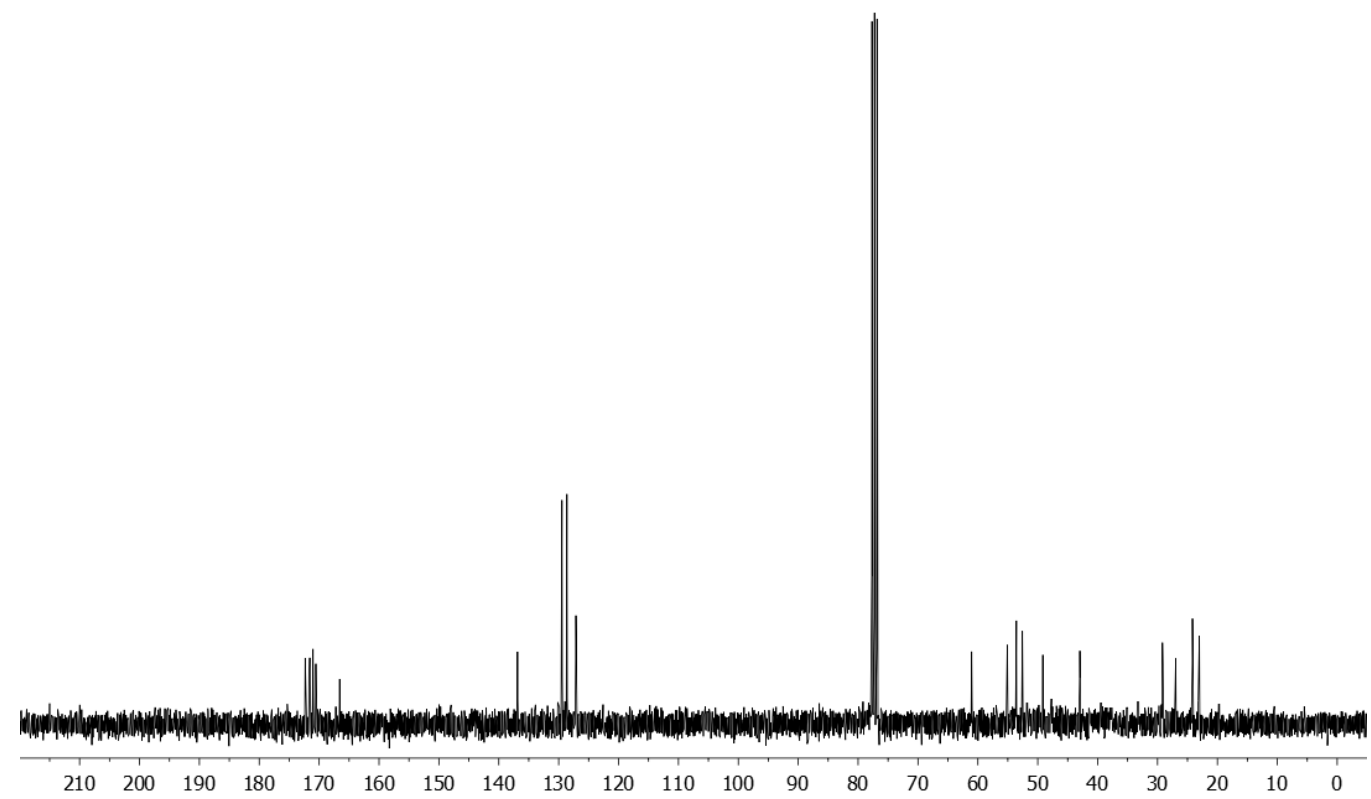

$75 \mathrm{MHz}{ }^{13} \mathrm{C}$ NMR for Ac-Cys[SS( $\left.\left.\mathrm{CH}_{2} \mathrm{CONH}_{2}\right)\right]$-Pro-Phe-OMe $\mathbf{6 k}$ in $\mathrm{CDCl}_{3}$ (ppm) 


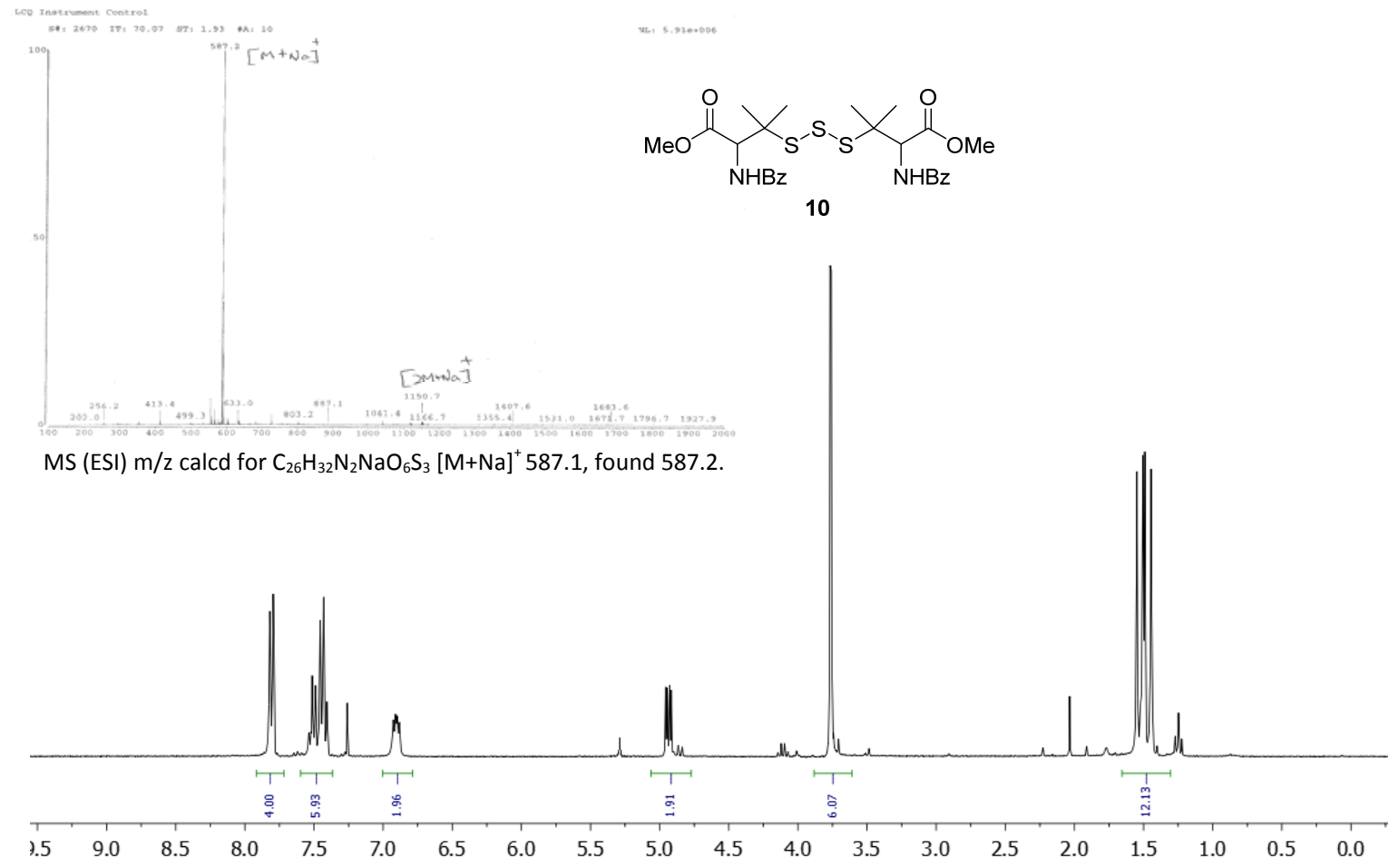

$300 \mathrm{MHz}^{1} \mathrm{H}$ NMR for Bz-DL-enicillamine[SSS-(Bz)-PL-penicillamine-OMe]-OMe 10 in $\mathrm{CDCl}_{3}(\mathrm{ppm})$

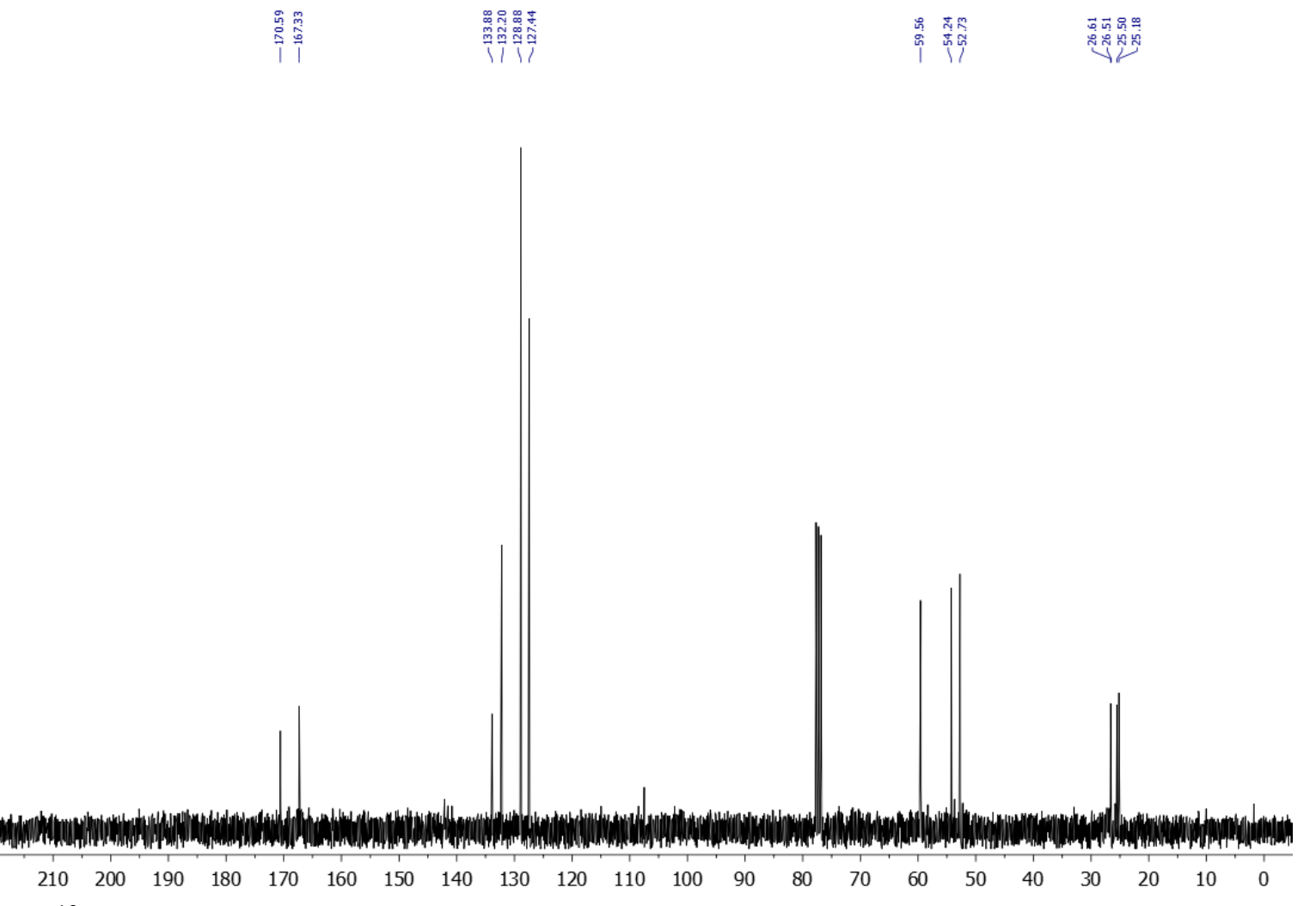

$75 \mathrm{MHz}{ }^{13} \mathrm{C}$ NMR for Bz-DL-penicillamine[SSS-(Bz)-DL-penicillamine-OMe]-OMe 10 in $\mathrm{CDCl}_{3}(\mathrm{ppm})$ 


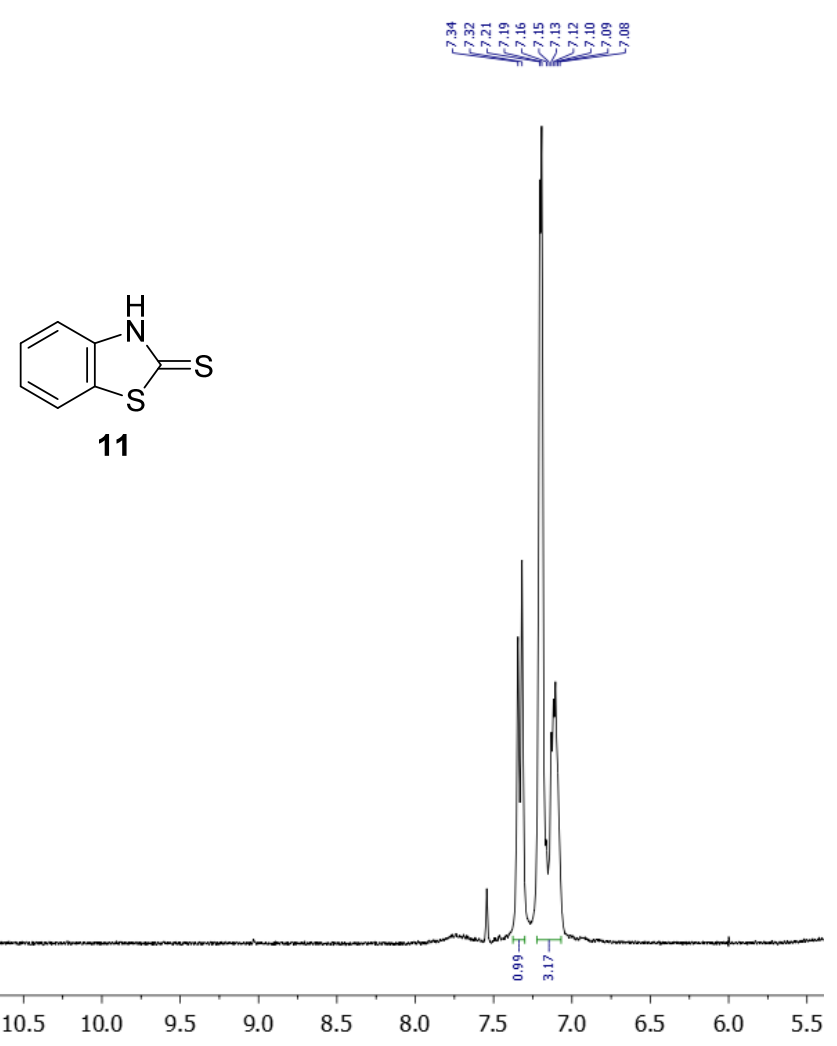

$300 \mathrm{MHz}{ }^{1} \mathrm{H}$ NMR for benzo[d]thiazole-2(3H)-thione 11 in $\mathrm{CDCl}_{3}+\mathrm{DMSO}_{6}(\mathrm{~d} p \mathrm{~d})$
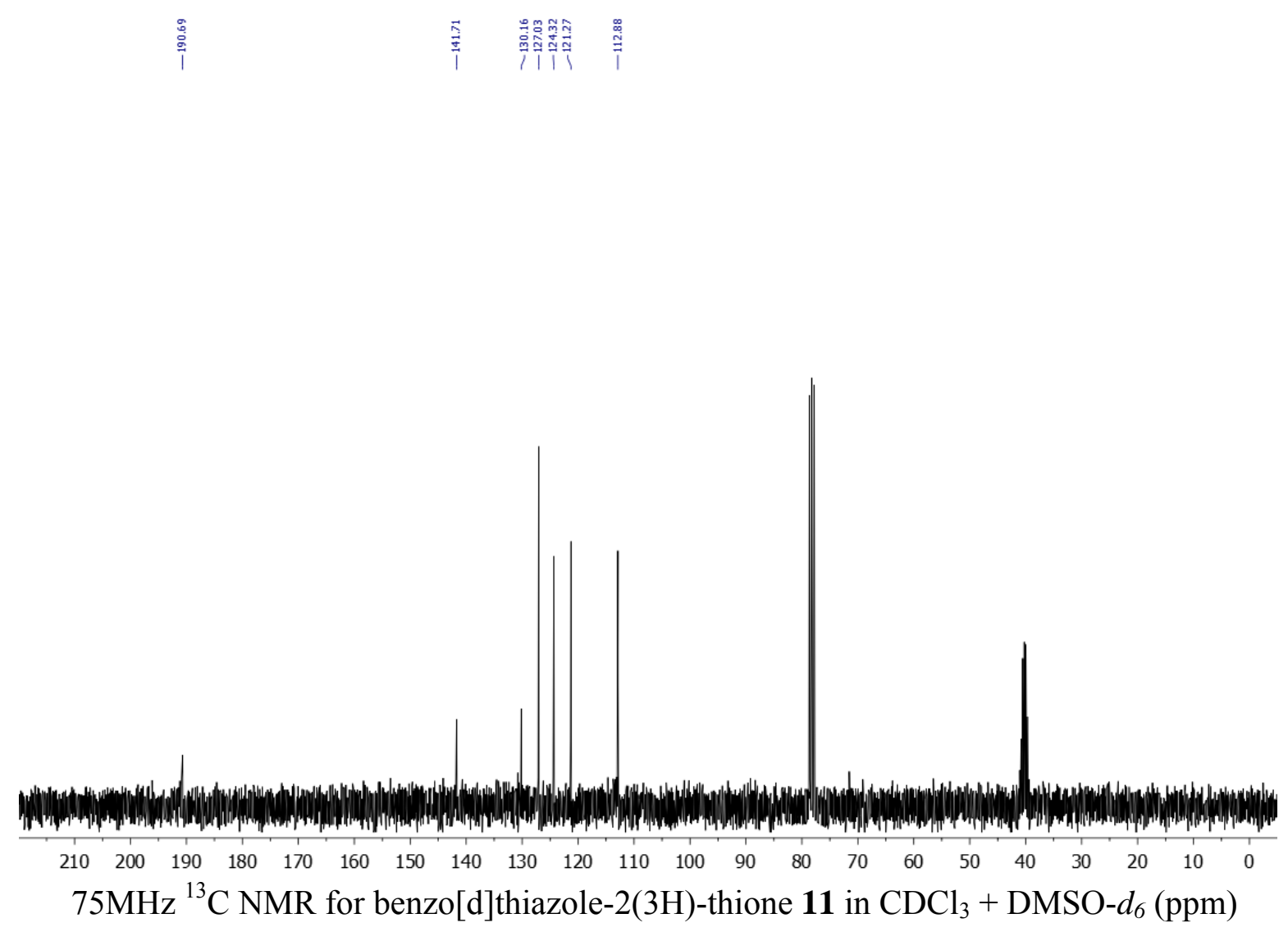


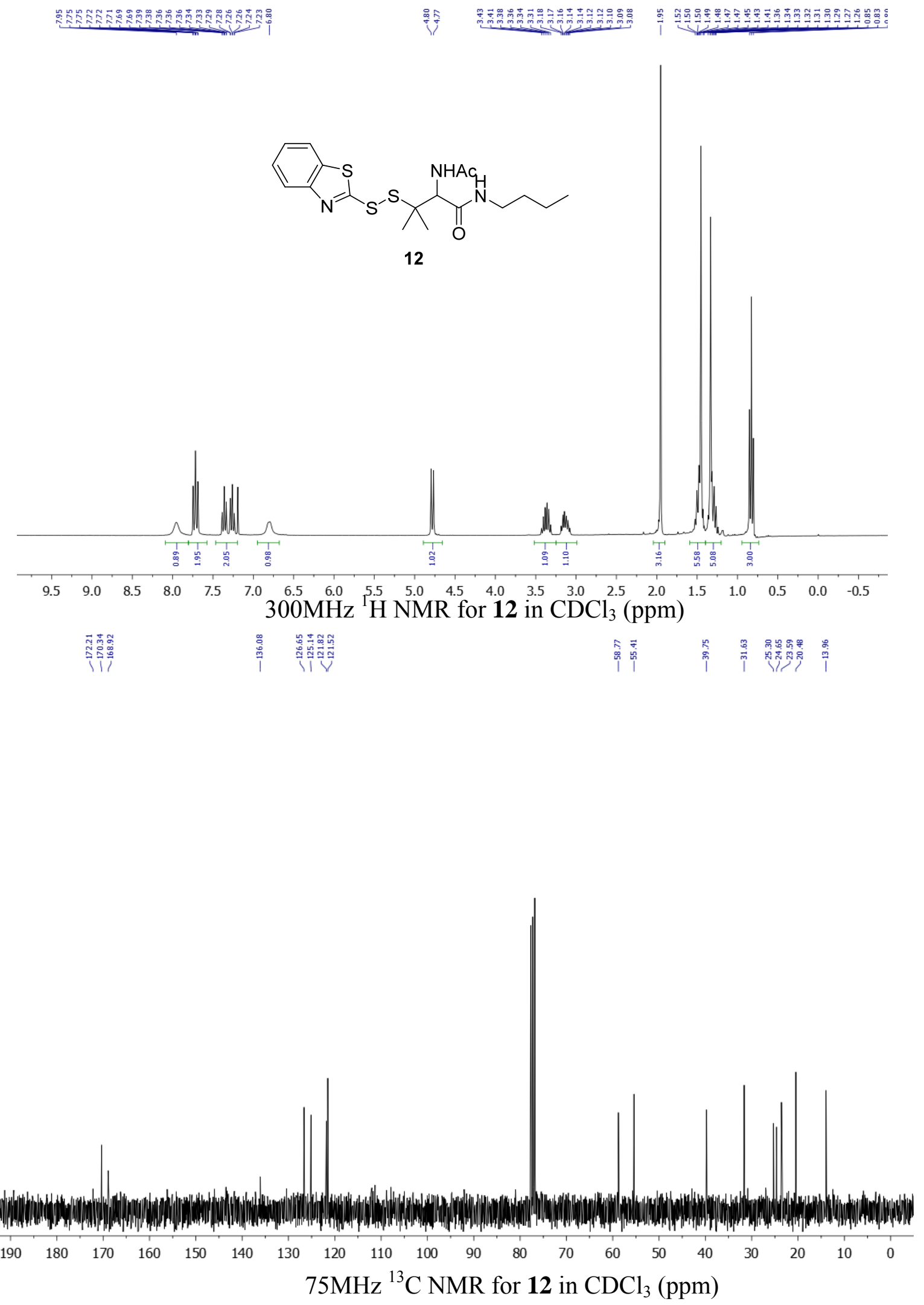



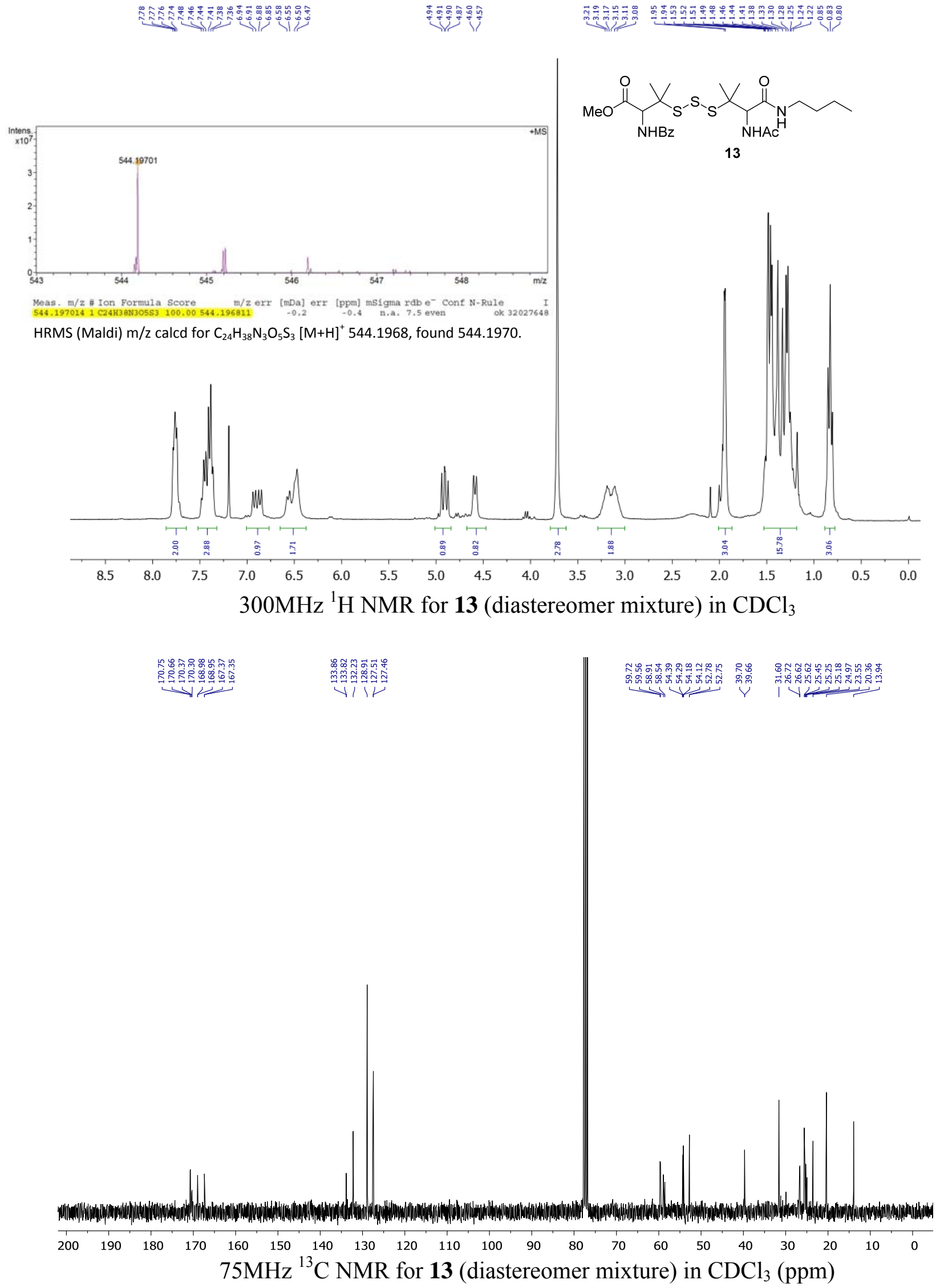